\title{
Removal of Malachite Green Dye from Aqueous Solutions onto Microwave Assisted Zinc Chloride Chemical Activated Epicarp of Ricinus communis
}

\author{
M. Makeswari, T. Santhi* \\ Department of Chemistry, Karpagam University, Coimbatore, India \\ Email: ${ }^{*}$ ssnilasri@yahoo.co.in
}

Received October 4, 2012; revised November 20, 2012; accepted January 15, 2013

\begin{abstract}
Competitive adsorption of malachite green (MG) in single and binary system on microwave activated epicarp of Ricinus communis (MRC) and microwave assisted zinc chloride activated epicarp of Ricinus communis (ZRC) were analyzed. The preparation of ZRC from Ricinus communis was investigated in this paper. Orthogonal array experimental design method was used to optimize the preparation of ZRC. Optimized parameters were radiation power of $100 \mathrm{~W}$, radiation time of $4 \mathrm{~min}$, concentration of zinc chloride of $30 \%$ by volume and impregnation time of $16 \mathrm{~h}$, respectively. The MRC and ZRC were characterized by pHzpc, SEM-EDAX and FTIR analysis. The effect of the presence of one dye solution on the adsorption of the other dye solution was investigated in terms of equilibrium isotherm and adsorption yield. Experimental results indicated that the uptake capacities of one dye were reduced by the presence of the other dye. The adsorption equilibrium data fits the Langmuir model well and follows pseudo second-order kinetics for the bio-sorption process. Among MRC and ZRC, ZRC shows most adsorption ability than MRC in single and binary system.
\end{abstract}

Keywords: Epicarp of Ricinus communis; Microwave Heating; Zinc Chloride; Binary System; Equilibrium Isotherm

\section{Introduction}

Dyes are widely used in industries such as textiles, leather, paper, plastics, etc. to color their final products. The textile industries are the greatest generators of liquid effluent, due to high quantity of water used in the dyeing processes [1]. Fifteen percent of the total world production of dyes is lost during the dyeing process and is released in textile effluent. Malachite Green (MG) is a cationic dye and widely used for the dyeing of leather, wool and silk, distilleries, jute, paper, as a food coloring agent, food additive, in medical disinfectant and fish industries [2,3]. Discharge of MG into the hydrosphere can cause environmental degradation as it gives undesirable color to water and reduces sunlight penetration. The consumption of MG has many adverse effects due to its carcinogenic, genotoxic, mutagenic and teratogenic properties of MG are due to presence of the nitrogen.

Dye removal from wastewater effluent is a major environmental problem because of the difficulty of treating such streams by conventional physical, chemical, physico-chemical and biological treatment methods. Many physical and chemical treatment methods including adsorption, coagulation, precipitation filtration, electrodi-

\footnotetext{
Corresponding author.
}

alysis, membrane separation and oxidation have been used for the treatment of dye-containing effluents [4]. Adsorption process is one of the most effective and economically feasible methods for the removal of dyes from aqueous solutions.

Activated carbon was widely used in removal dyes from textile effluent, which had relatively high sorption capacity for a wide variety of dyes. Commercially available activated carbons are usually derived from natural materials such as wood or coal, therefore, are still considered expensive [5]. Due to economical reasons, it was investigated for a long time that agricultural byproducts and waste materials used for the production of activated carbon. Examples of these attempts included rattan sawdust [6], rice husk [7], lemon peel [8], granular kohlrabi [9], jute fiber [10] and coconut husk [11].

Two methods are used for the preparation of AC via, physical and chemical activation. During physical activation, the raw material is carbonized first at high temperature and then it is activated by $\mathrm{CO}_{2}$ or steam under pressure to increase porosity and surface area of AC. In chemical activation both carbonization and activation takes place simultaneously, in which raw material is first impregnated with activating chemical and then carbonized at desired temperature that varies according to acti- 
vating chemical used [12]. The development of porous structure is better in the case of chemical activation [13]. Chemical activation is held in presence of dehydrating reagents such as $\mathrm{KOH}, \mathrm{K}_{2} \mathrm{CO}_{3}, \mathrm{NaOH}, \mathrm{ZnCl}_{2}$ and $\mathrm{H}_{3} \mathrm{PO}_{4}$ which influence pyrolytic decomposition and inhibit tar formation. The carbon yield obtained is higher and the temperature used in chemical activation is lower than that of physical activation. Behaviors of the reagents during chemical activation show different effects on the final product. $\mathrm{ZnCl}_{2}$ is the widely used as activating reagent, since it resulted in high surface areas and high yield $[14,15]$. In the use of $\mathrm{ZnCl}_{2}$, the activated carbons had large surface areas and more micro pore structure $[8$, 10]. For preparing activated carbon, conventional heating method is usually adopted, in which the energy is produced by electrical furnace. Recently, microwave heating technology has been applied to fabricate activated carbon due to its rapid heating and uniformity [15].

The application of microwave (MW) heating technology for regenerating industrial waste activated carbon has been investigated with very promising results $[16$, 17]. The main difference between MW devices and conventional heating systems is in the way of t heating. In the MW device, the microwaves supply energy directly to the carbon bed. Energy transfer is not by conduction or convection as in conventional heating, but microwave energy is readily transformed heat into inside the particles by dipole rotation and ionic conduction [16-18]. Recently microwave energy has been widely using in several fields of applications on both research and industrial processes. Although the use of microwave energy changes the properties of carbonaceous materials very much, there are relatively few publications that describe the use of microwaves for producing and regenerating activated carbons. Nabasis et al., studied on the surface chemistry modification of activated carbon fibres by means of microwave heating which was found to be very effective. Microwave is now being used in various fields in order to heat dielectric materials because it can considerably shorten the treatment time and reduce energy consumption.

The aim of the present work was to optimize the MRC and ZRC preparation conditions using orthogonal array experimental design method, investigate the ability of a malachite green dye sorbent prepared from epicarp of Ricinus communis (RC) is an agricultural waste material by microwave assisted chemical activation using zinc chloride as activating agent for the adsorption of malachite green dye from aqueous solution. The adsorption ability of classical activated Ricinus communis was previously investigated for the adsorption of MG dye from aqueous solution [19].

The objective of the present study is to evaluate the possibility of using the dried epicarp of Ricinus commu- nis to develop a new low-cost activated carbon and to study the effect of several parameters $(\mathrm{pH}$, contact time, initial metal concentration, $\mathrm{pH}_{\mathrm{zpc}}$, adsorption isotherms and kinetics) on the adsorption efficiency of malachite green (MG) dye from aqueous solution in single and binary system and compare the performance of MRC and $\mathrm{ZRC}$ for the adsorption of MG in single (MG) and binary system (MG + Methylene blue).

\section{Experimental}

\subsection{Materials}

Samples of Malachite green (MG) and Methylene blue (MB) were obtained from Aluva, Edayar (specrum reagents and chemicals pvt. Ltd). All other chemicals used in this study were analytical grade and Purchased from Aluva, Edayar (specrum reagents and chemicals pvt. Ltd) and was used without any further purification. The chemical structure of malachite green is shown in Figure 1. Malachite green hydrochloride $($ C.I. $=42,000)$ has the molecular formula of $\mathrm{C}_{23} \mathrm{H}_{25} \mathrm{ClN}_{2}$, the molecular weight of $364.92, \lambda_{\max }=617 \mathrm{~nm}$.

A Stock solution of $500 \mathrm{mg} / \mathrm{L}$ was prepared by dissolving accurately weighed amounts of MG in doses of $1000 \mathrm{~mL}$ distilled water. The desirable experimental concentrations of solutions were prepared by diluting the stock solution with distilled water when necessary.

\subsection{Preparation of Adsorbent}

\subsubsection{Preparation of Microwave Treated Ricinus communis (MRC)}

The epicarp of Ricinus communis (RC) was obtained from an agricultural form in Tirupur district (TamilNadu). It was air-dried and powdered in a grinder. Dried Ricinus communis with the mass of $6 \mathrm{~g}$ were placed in a MW heating apparatus (MW71E) which produced by SAMSUNG, Malaysia. After a certain heating power of 100 $\mathrm{W}$ and microwave radiation time of $4 \mathrm{~min}$, and finally dried at $150^{\circ} \mathrm{C}$ in a hot air oven. The MRC was then stored in an air-tight container for later experimental use.

\subsubsection{Preparation of Zinc Chloride Assisted Ricinus communis (ZRC)}

The epicarp of Ricinus communis was obtained from the<smiles>CN(C)c1ccc(C(=C2C=CC(=[N+](C)[O-])C=C2)c2ccccc2)cc1</smiles>

Figure 1. Chemical structure of malachite green. 
agricultural form in Tirupur district (Tamil Nadu). It was air-dried and powdered in a grinder. Dried Ricinus communis with the mass of $6 \mathrm{~g}$ were mixed with $30 \mathrm{~mL}$ of $\mathrm{ZnCl}_{2}$ to vary concentrations in the range of $30 \%-60 \%$ by volume. The slurry was kept at room temperature for various time spans in the range of $16-28 \mathrm{~h}$ to ensure the access of the $\mathrm{ZnCl}_{2}$ to the Ricinus communis. After mixing, the slurry was placed in a MW heating apparatus (MW71E, SAMSUNG). After a heating power of $100 \mathrm{~W}$ $600 \mathrm{~W}$ and microwave radiation time of $10 \mathrm{~min}-4 \mathrm{~min}$, the carbonized sample were washed with $0.5 \mathrm{M} \mathrm{HCl}$, hot water and cold distilled water until the $\mathrm{pH}$ of the washing solution reached $6-7$, filtered and finally dried at $150^{\circ} \mathrm{C}$ in hot air oven for $6 \mathrm{~h}$. The ZRC was then stored in an air-tight container for later experimental use.

\subsection{Optimization of ZRC Preparation Conditions}

In order to optimize the preparation conditions of the ZRC, Taguchi experimental design method was used [19]. An $\mathrm{L}_{16}$ orthogonal array with four operational parameters each in four levels was used to evaluate the corresponding optimal values. These variables and their values are summarized in Table 1. The complete design matrix of the experiments and the obtained results are shown in Table 2. Iodine is considered as probe molecules for assessing the adsorption capacity of adsorbents for solutes of molecular sizes less than $10 \AA$. Iodine number was normally listed as specification parameter for ZRC. Therefore, the responses were iodine number $\left(\mathrm{Y}_{2}, \mathrm{mg} / \mathrm{g}\right)$, yield $\left(\mathrm{Y}_{1}, \%\right)$ was obtained at $25^{\circ} \mathrm{C} \pm 1^{\circ} \mathrm{C}$ on the basis of the standard Test method. The yield of the carbon samples was estimated according to,

$$
\mathrm{Y}=\frac{\mathrm{M}}{\mathrm{M}_{0}} \times 100
$$

where $M$ is the weight of $M R C$ and $Z R C$ and $M_{0}$ is the weight of air dried Ricinus communis leaves.

\subsection{Effect of Independent Variables on ZRC Preparation Conditions}

According to the $\mathrm{L}_{16}$ array designed by Taguchi method,

Table 1. Design and levels.

\begin{tabular}{cccccc}
\hline & & \multicolumn{5}{c}{ Range and levels } \\
\cline { 3 - 6 } Independent variables & Symbol & 1 & 2 & 3 & 4 \\
\hline Radiation power (W) & $\mathrm{A}$ & 100 & 200 & 400 & 600 \\
Radiation time (min) & $\mathrm{B}$ & 10 & 8 & 6 & 4 \\
Concentration of $\mathrm{ZnCl}_{2}(\mathrm{vol} \%)$ & $\mathrm{C}$ & 30 & 40 & 50 & 60 \\
Impregnation time (h) & $\mathrm{D}$ & 16 & 20 & 24 & 28 \\
\hline
\end{tabular}

Table 2. Experimental design matrix and results.

\begin{tabular}{ccccccc}
\hline & \multicolumn{3}{c}{ Variables } & \multicolumn{2}{c}{ Responses (Y) } \\
\cline { 2 - 6 } & A & B & C & D & $\begin{array}{c}\text { Iodine number } \\
\left(\mathrm{y}_{1}, \mathrm{mg} / \mathrm{g}\right)\end{array}$ & $\begin{array}{c}\text { Yield of ZRC } \\
\left(\mathrm{y}_{2}, \%\right)\end{array}$ \\
\hline 1 & 1 & 1 & 1 & 1 & 466.0 & 35.74 \\
2 & 2 & 1 & 1 & 1 & 698.56 & 54.88 \\
3 & 3 & 1 & 1 & 1 & 910.16 & 72.21 \\
4 & 4 & 1 & 1 & 1 & 783.16 & 69.68 \\
5 & 1 & 1 & 1 & 1 & 635.0 & 43.98 \\
6 & 1 & 2 & 1 & 1 & 973.66 & 53.32 \\
7 & 1 & 3 & 1 & 1 & 1164.6 & 58.75 \\
8 & 1 & 4 & 1 & 1 & 466.00 & 35.74 \\
9 & 1 & 1 & 1 & 1 & 466.0 & 35.74 \\
10 & 1 & 1 & 2 & 1 & 762.33 & 52.62 \\
11 & 1 & 1 & 3 & 1 & 804.33 & 63.11 \\
12 & 1 & 1 & 4 & 1 & 719.66 & 56.94 \\
13 & 1 & 1 & 1 & 1 & 466.0 & 35.74 \\
14 & 1 & 1 & 1 & 2 & 740.83 & 42.16 \\
15 & 1 & 1 & 1 & 3 & 402.16 & 52.95 \\
16 & 1 & 1 & 1 & 4 & 825.5 & 55.97 \\
\hline & & & & & & \\
\hline
\end{tabular}

16 different ZRC samples were prepared. Iodine number and yield of each sample were determined and shown in Table 2. The effect of operational parameters on responses of the prepared ZRC samples is shown in Figure 2.

\subsubsection{Effect of Microwave Radiation Power on the Yield and Iodine Number of ZRC}

Effect of microwave radiation power (Parameter A) on adsorption capacity and the yield of ZRC were evaluated under the concentration of $\mathrm{ZnCl}_{2}\left(\mathrm{X}_{\mathrm{Zn}}\right)$ of $30 \mathrm{ml}$ and microwave radiation time of $4 \mathrm{~min}$. Figure 2 shows that the yield of ZRC samples were increased with the increasing of microwave power level from $100-400 \mathrm{~W}$, and then decreased with increasing of the level of $600 \mathrm{~W}$. There were similar tendency of the iodine number on ZRC. The possible reason was that the higher energy was offered to the samples with increasing the power level, the more active sites and pores on the samples. When microwave power reached a certain level, overfull energy could make a small quantity of carbon burnt, and the structure of pores was destroyed. Similar results have been obtained by other researchers [9,21].

\subsubsection{Effect of Microwave Radiation Time on the Yield and Iodine Number of ZRC}

Effects of microwave radiation time (parameter B) on the 


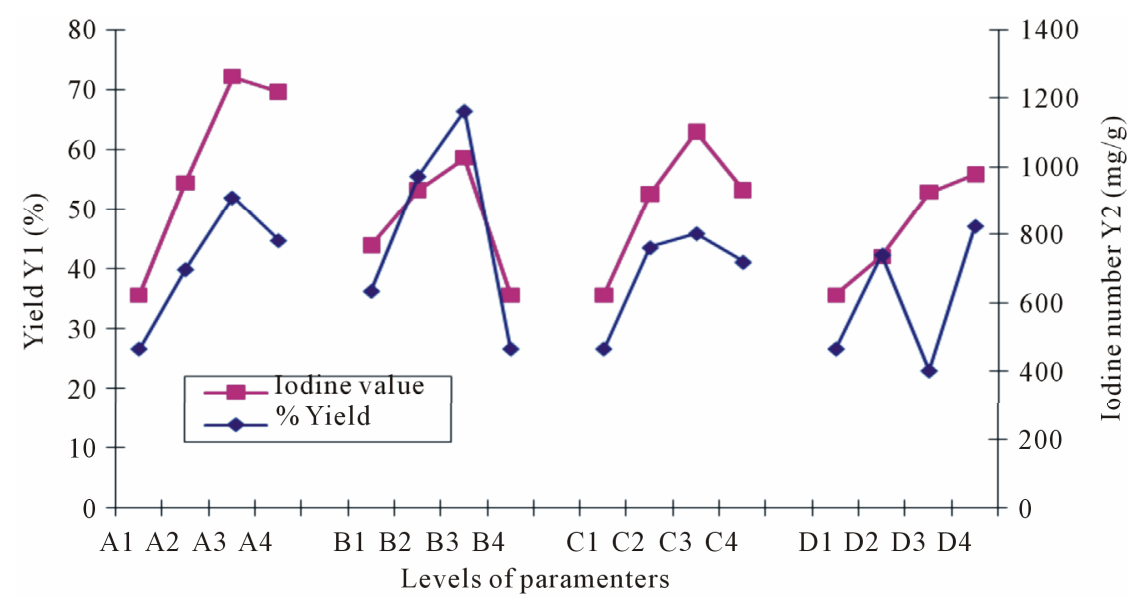

Figure 2. The effect of operational parameters on responses of the prepared ZRC samples. ((A) Radiation power; (B) Radiation time; (C) Concentration of $\mathrm{ZnCl}_{2}$ and (D) Impregnation time).

yield and iodine number of ZRC were evaluated, under the conditions of $X_{\mathrm{Zn}}$ of $30 \mathrm{ml}$ and microwave power of $100 \mathrm{~W}$ (Figure 2). It revealed that the yield of ZRC was increased with increasing the radiation time up to $8 \mathrm{~min}$, and then decreased, when the time was increased to 10 $\min$. There were same tendency of the iodine number of ZRC. Similar trends were also found by Li et al., when they prepared the activated carbon from tobacco stems using microwave radiation [22]. The activation degree was much more dependent on the microwave radiation time. With the prolongation of microwave radiation time, much more active sites and pores were formed on the surface of samples. Therefore the adsorption capacity of ZRC would be increased with the prolongation of microwave radiation time. However, when microwave radiation time reached a certain value, the pores of carbon would be burnt off by microwave heating, which would lower the iodine number, the amount of nickel uptake and the yield of ZRC.

\subsubsection{Effect of Impregnation Ratio of $\mathrm{ZnCl}_{2}$ and Impregnation Time on the Yield and Iodine Number of ZRC}

Under the microwave power of $100 \mathrm{~W}$, radiation time of $8 \mathrm{~min}$, the effects of the impregnation ratio (parameter $\mathrm{C}$ ) of $\mathrm{ZnCl}_{2}$ on the yield and iodine number of $\mathrm{ZRC}$ was studied (Figure 2). With the increasing $\mathrm{X}_{\mathrm{Zn}}$ from $30 \mathrm{ml}$ to $90 \mathrm{ml}$, the yield, the iodine number and the amount of MG adsorption of ZRC were all increased. While $\mathrm{X}_{\mathrm{Zn}}$ was further increased to $120 \mathrm{ml}$, these two parameters were all decreased. With increase in impregnation ratio, the initial effect of $\mathrm{ZnCl}_{2}$ is to inhibit the release of volatile matter, which results in higher yield and iodine number of ZRC. Subsequently, with the further increase in impregnation ratio, the zinc chloride assumed a dehydration agent role during activation. It inhibits the formation of tars and any other liquids that could clog up the pores of the sample, the movement of the volatiles through the pore passages would not be hindered, the volatiles will be subsequently released from the carbon surface during activation. Therefore the yield and iodine number of carbon were all decreased. Similar trends were also reported by Lua and Yang [23], Guo and Lua [24] in their studies on the preparation of activated carbon from pistachio-nut shell and oil-palm shells, respectively.

The results presented in Figure 2 also shows that impregnation time (parameter D) had little influence on the yield and iodine number. The action of $\mathrm{ZnCl}_{2}$ on the lignocellulosic material could be expressed as the following mechanism.

During impregnation stage the base attacked the cellular structure of Ricinus communis leaves, forming cleavage to the linkages between the lignin and cellulose. It was followed by recombination reactions, where larger structural units and strong cross linked solids were formed. This base worked, principally, in early stage during impregnation and might extended to have a slight effect in the carbonization stage [25].

\subsection{Optimized Conditions}

In the production of $\mathrm{AC}$, relatively high product yield and adsorption capacity were expected. Therefore, more attention should be paid to improve the carbon yield and enhance its adsorption capacity for economical viability. However, it was difficult to optimize both these responses under the same condition, for the different interest in different region. From the discussions mentioned above, the microwave radiation power, microwave radiation time, impregnation ratio and the impregnation time of $\mathrm{ZnCl}_{2}$ had significant effects on the yield and the adsorption capacity of the activated carbon from Ricinus communis leaves with $\mathrm{ZnCl}_{2}$ activation by microwave radiation. Therefore the optimum conditions were ob- 
tained as following: the microwave power of $100 \mathrm{~W}$, microwave radiation time of $4 \mathrm{~min}, X_{\mathrm{Zn}}$ of $30 \mathrm{ml}$ and impregnation time of $16 \mathrm{~h}$. Iodine number and the yield of activated carbon prepared under optimum conditions were $69.68 \%$ and $783.16(\mathrm{mg} / \mathrm{g})$, respectively. The ZRC was used in the characterization analysis and adsorption experiments which were prepared under optimum conditions.

\subsection{Characterization of MRC and ZRC}

The surface morphology of MRC and ZRC were identified by using SEM technique (Jeol jsm-6390). A Fourier transforms infrared spectroscopy (SHIMADZU, IR Affinity-1) with $\mathrm{KBr}$ pellet was used to study surface functional groups of the MRC and ZRC, with a scanning range of $4000-400 \mathrm{~cm}^{-1}$. The zero surface charges $\left(\mathrm{pH}_{\mathrm{ZPC}}\right)$ of MRC and $\mathrm{ZRC}$ were determined by using the solid addition method [20]. The acidity and Basicity of MRC and ZRC were determined and confirmed by Boehm's titration method. The ability of the MRC and ZRC in the adsorption of $\mathrm{MG}$ in single (MG) and binary system $(\mathrm{MG}+\mathrm{MB})$ were investigated by batch isotherm and kinetic studies. The concentration of MG in single and binary system were determined using a double beam UV-vis spectrophotometer (SHIMADZU UV-2450) of the wavelength of $617 \mathrm{~nm}$.

\subsection{Batch Equilibrium Studies}

To study the effect of parameters such as adsorbent dose, dye concentration and solution $\mathrm{pH}$ for the removal of adsorbate on MRC and ZRC, batch experiments were performed. Stock solutions of $\mathrm{MG}$ in single and binary system were prepared by dissolving $\mathrm{MG}(\mathrm{S})$ and $\mathrm{MG}+$ $\mathrm{MB}$ (B) in deionized water and further diluted to the 50 $200 \mathrm{mg} / \mathrm{L}$ concentrations for the experiments. $\mathrm{pH}$ was adjusted by adding $0.1 \mathrm{M} \mathrm{HCl}$ or $0.1 \mathrm{M} \mathrm{NaOH}$ into the solutions with known initial MG concentrations. Batch adsorption experiments were conducted in asset of 250 $\mathrm{mL}$ stoppered flasks containing $0.2 \mathrm{~g}$ of MRC and ZRC and $50 \mathrm{~mL}$ of dye solutions with different concentrations $(50,100,150$ and $200 \mathrm{mg} / \mathrm{L})$ at $\mathrm{pH} 5$. The flasks were agitated using a mechanical orbital shaker, and maintained at room temperature for $2 \mathrm{~h}$ until the equilibrium was reached. The suspensions were filtered and dye concentrations in the supernatant solutions were measured using a UV-vis spectrophotometer at $617 \mathrm{~nm}$. The amounts of uptake of MG by MRC and ZRC in the equilibrium $\left(\mathrm{q}_{\mathrm{e}}\right)$ were calculated by the following mass-balance relationship

$$
\mathrm{q}_{\mathrm{e}}=\frac{\left(\mathrm{C}_{\mathrm{o}}-\mathrm{C}_{\mathrm{e}}\right)}{\mathrm{W}} \times \mathrm{V}
$$

where $\mathrm{C}_{\mathrm{o}}$ and $\mathrm{C}_{\mathrm{e}}(\mathrm{mg} / \mathrm{L})$ are the liquid phase concentra- tions of dye at initial and equilibrium, respectively. V (L) is the volume of the solution, and $\mathrm{W}(\mathrm{g})$ is the mass of adsorbent used.

Adsorption isotherm is the most important information which indicates how the adsorbate molecules distribute between the liquid phase and the solid phase when adsorption process reaches on equilibrium state. When the system is at equilibrium is of importance in determining the maximum sorption capacity of MRC and ZRC towards dyes.

\subsubsection{Effect of Adsorbent Dose}

To observe the effect of adsorbent dose on dye adsorption, different amounts of adsorbent varying from $0.2 \mathrm{~g} /$ $50 \mathrm{ml}, 0.4 \mathrm{~g} / 50 \mathrm{ml}, 0.6 \mathrm{~g} / 50 \mathrm{ml}, 0.8 \mathrm{~g} / 50 \mathrm{ml}$ and $1 \mathrm{~g} / 50$ $\mathrm{ml}$ were added into initial concentration of $100 \mathrm{mg} / \mathrm{L} \mathrm{MG}$ in single and binary solution. The mixtures were shaken in $250 \mathrm{~mL}$ stoppered flasks at room temperature at $\mathrm{pH} 5$ until the equilibrium time was reached.

\subsubsection{Effect of Solution $\mathrm{pH}$}

To study the effect of solution $\mathrm{pH}$ on MG adsorption, $100 \mathrm{mg} / \mathrm{L}$ initial concentration at different $\mathrm{pH}$ values (2 9) was agitated with $0.2 \mathrm{~g}$ of MRC and ZRC in a mechanical orbital shaker at room temperature. The effect of $\mathrm{pH}$ on $\mathrm{MG}$ adsorption was studied by varying the $\mathrm{pH}$ from 2.0 to 9.0. The concentration of MG solution used for this study was $100 \mathrm{mg} / \mathrm{L}$ and the adsorbent dose was $0.2 \mathrm{~g}$. The initial $\mathrm{pH}$ was written as $\mathrm{pH}_{\mathrm{i}}$ and the solution $\mathrm{pH}$ after adsorption was also measured and written as $\mathrm{pH}_{\mathrm{f}}$. The $\mathrm{pH}$ was adjusted with $0.1 \mathrm{M} \mathrm{NaOH}$ and $0.1 \mathrm{M} \mathrm{HCl}$ solutions.

\subsubsection{Effect of Initial Dye Concentration}

In order to study the effect of initial dye concentration on the adsorption uptake, MG solutions with initial concentrations of $50-200 \mathrm{mg} / \mathrm{L}$ with varying the adsorbent dose of $0.2 \mathrm{~g} / 50 \mathrm{~mL}$ of MRC and ZRC respectively. In this case, the solution $\mathrm{pH}$ was kept as 5 .

\section{Results and Discussion}

\subsection{Surface Acidity and Basicity}

Surface acidity was estimated by mixing $0.2 \mathrm{~g}$ of MRC and ZRC with $25 \mathrm{~mL}$ of $0.5 \mathrm{M} \mathrm{NaOH}$ in a closed flask, the flask was agitated for $48 \mathrm{~h}$ at room temperature $\left(28^{\circ} \mathrm{C}\right)$. The Suspension was decanted and the remaining $\mathrm{NaOH}$ was titrated with $0.5 \mathrm{M} \mathrm{HCl}$. The surface basicity was measured by titration with $0.5 \mathrm{M} \mathrm{NaOH}$ after agitation of $0.2 \mathrm{~g}$ of MRC and ZRC with $0.5 \mathrm{M} \mathrm{HCl}$. MRC has the surface acidity of $1.803 \mathrm{mmol} / \mathrm{g}$ and $4.06 \mathrm{mmol} / \mathrm{g}$ surface basicity and ZRC has the surface acidity of 2.73 $\mathrm{mmol} / \mathrm{g}$ and $2.53 \mathrm{mmol} / \mathrm{g}$ surface basicity. Acidity and basicity were confirmed by Boehm titration method. 
Boehm titrations quantify the basic and oxygenated acidic surface groups on activated carbons [21].

\subsection{Zero Surface Charges-The Characteristic Analysis of MRC and ZRC}

The influence on the solution $\mathrm{pH}$ on the dye uptake can be explained on the basis of the $\mathrm{pH}$ zero point charge or isoelectric point of the adsorbent. The value of the $\mathrm{pH}$ necessary to affect a net zero charge on a solid surface in the absence of specific sorption is called the point of zero charge, $\mathrm{pH}_{\mathrm{ZPC}}$.

The zero surface charge of MRC and ZRC were determined by using the solid addition method [20]. The experiment was conducted in a series of $250 \mathrm{~mL}$ glass stoppered flasks. Each flask was filled with $50 \mathrm{~mL}$ of different initial $\mathrm{pH} \mathrm{NaNO}_{3}$ solutions and $0.2 \mathrm{~g}$ of MRC and ZRC. The $\mathrm{pH}$ values of the $\mathrm{NaNO}_{3}$ solutions were adjusted between 2 to 9 by adding either $0.1 \mathrm{M} \mathrm{HNO}_{3}$ or $0.1 \mathrm{M} \mathrm{NaOH}$. The suspensions were then sealed and shaken for $2 \mathrm{~h}$ at $150 \mathrm{rpm}$. The final $\mathrm{pH}$ values of the supernatant liquid were noted. The difference between the initial $\mathrm{pH}\left(\mathrm{pH}_{0}\right)$ and final $\mathrm{pH}\left(\mathrm{pH}_{\mathrm{f}}\right)$ values $\left(\mathrm{pH}=\mathrm{pH}_{0}\right.$ $-\mathrm{pH}_{\mathrm{f}}$ ) was plotted against the values of $\mathrm{pH}_{0}$. The point of intersection of the resulting curve with abscissa, gave the $\mathrm{pH}_{\mathrm{zpc}}$.

Figures 3(a) and (b) shows that the plot between $\Delta \mathrm{pH}$, i.e. $\left(\mathrm{pH}_{0}-\mathrm{pH}_{\mathrm{f}}\right)$ and $\mathrm{pH}_{0}$ for $\mathrm{pH}_{\mathrm{ZPC}}$ measurement for MRC and ZRC. The point of zero charge for MRC is found to be 3.14 and for ZRC is 4 . This result indicated that the $\mathrm{pH}_{\mathrm{ZPC}}$ of MRC and $\mathrm{ZRC}$ were depended on the raw material and the activated carbon. The zero point charge $\left(\mathrm{pH}_{\mathrm{ZPC}} 3.14\right.$ for $\mathrm{MRC}$ and $\mathrm{pH}_{\mathrm{ZPC}} 4$ for $\left.\mathrm{ZRC}\right)$ is below the solution $\mathrm{pH}(\mathrm{pH} 5)$ and hence the negative charge density on the surface of MRC and ZRC increased which favours the adsorption of cationic dye [22].

\subsection{Functional Group Analysis of MRC and ZRC}

The aim of using FTIR analysis is to determine the existence of functional groups and identification of characteristic peaks is based on the studies reported in the literature [23-25]. The FTIR spectrum of MRC and ZRC were shown in Figures 4(a) and (b). The absorption bands identify in the spectra and it revealed corresponding functional groups.

The broad band at about $3406.29 \mathrm{~cm}^{-1}$ was observed, which was assigned to the $\mathrm{O}-\mathrm{H}$ stretching vibration of the hydroxyl functional groups including hydrogen bonding. The intense bent at about $2927.94 \mathrm{~cm}^{-1}$ for the precursor was attributed to the $\mathrm{C}-\mathrm{H}$ stretching vibration. The peak at $1639.49 \mathrm{~cm}^{-1}$ was characteristics of the $\mathrm{C}=\mathrm{O}$ stretching vibration of lactonic and carbonyl groups. The peaks occurring at $1396.46 \mathrm{~cm}^{-1}, 1185.00 \mathrm{~cm}^{-1}$ were all as-

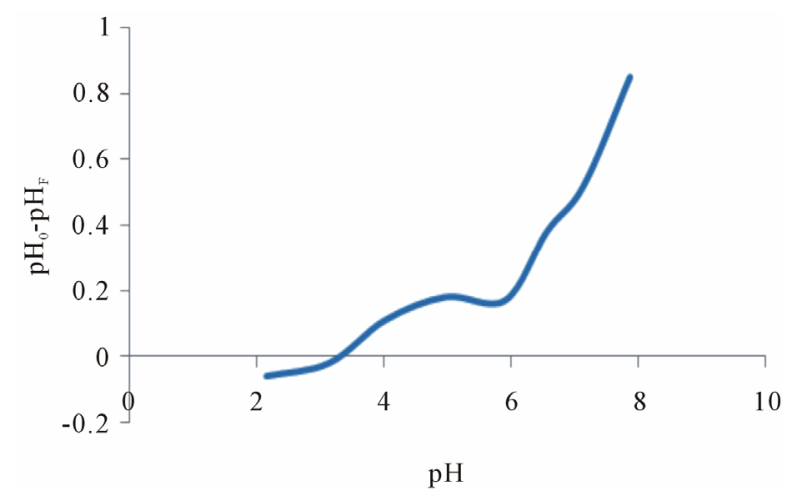

(a)

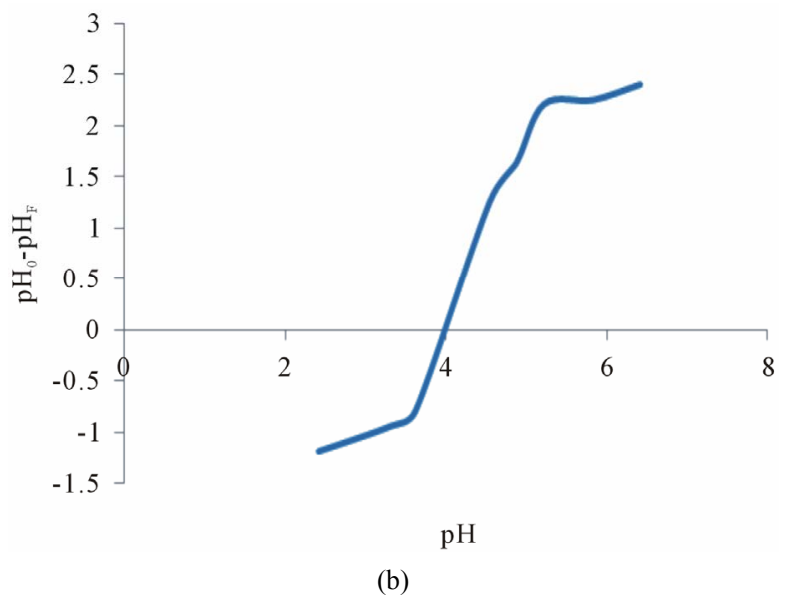

(b)

Figure 3. Zero point charges of (a) MRC and (b) ZRC.

cribed to oxygen functionalities such as highly conjugated $\mathrm{C}-\mathrm{O}$ stretching, $\mathrm{C}-\mathrm{O}$ stretching in carboxylic groups, and carboxylate moieties. The band located at $2352.6 \mathrm{~cm}^{-1}$ and $2332.6 \mathrm{~cm}^{-1}$ are attributed to the $\mathrm{C} \equiv \mathrm{C}$ stretching is due to the $\mathrm{ZnCl}_{2}$ activation [26].

\subsection{Scanning Electron Microscopic (SEM) Studies}

Scanning electron microscopy was used to study the surface morphology and the pore size of the samples. Samples of MRC and ZRC were subjected to SEM studies and SEM micrograph (Figures 5(a) and (b)) shows many orderly and developed pores.

It can be seen from the micrographs that the external surface of ZRC is full of cavities compared with MRC, and quite irregular as a result of activation and the pores were different sizes and different shapes. According to the micrograph, it seems that the cavities resulted from the evaporation of $\mathrm{ZnCl}_{2}$ during carbonization, leaving the space previously occupied by the $\mathrm{ZnCl}_{2}$. It is clear that the adsorbent has considerable number of heterogeneous pores where there is a good possibility for dye to be trapped and adsorbed [27].

Based on the EDAX results, the elementary analysis of 


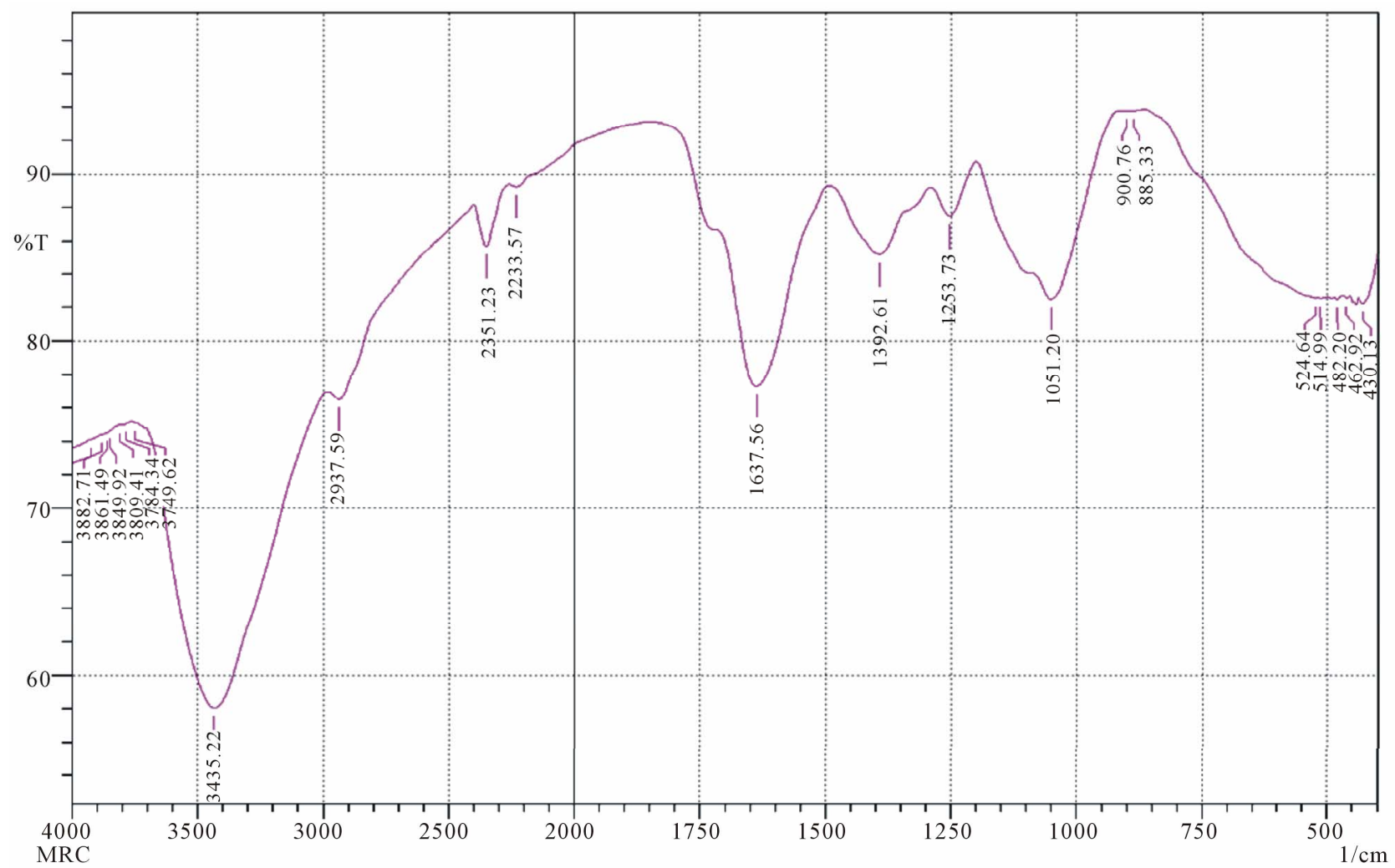

(a)

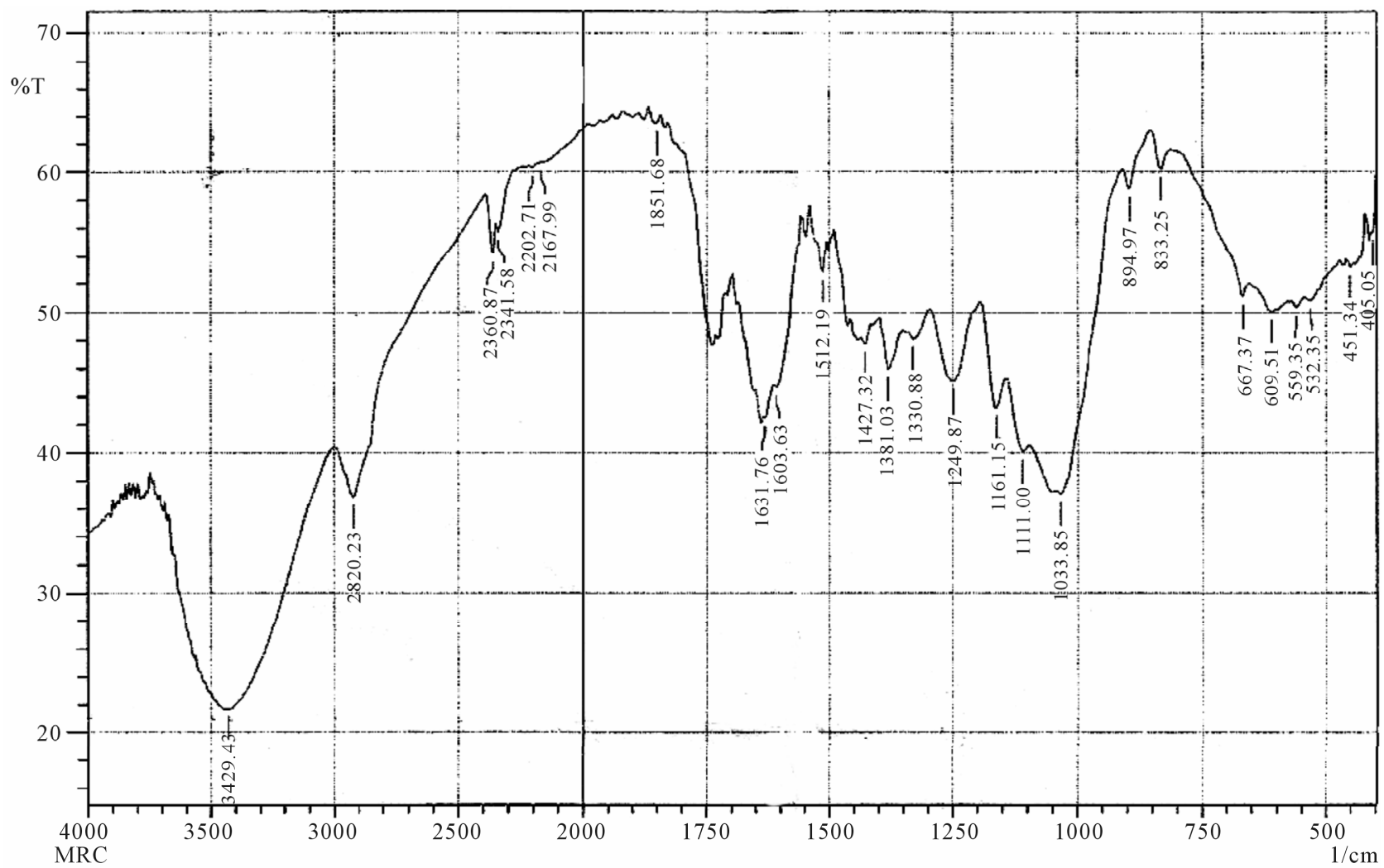

(b)

Figure 4. FTIR spectra of (a) MRC and (b) ZRC. 


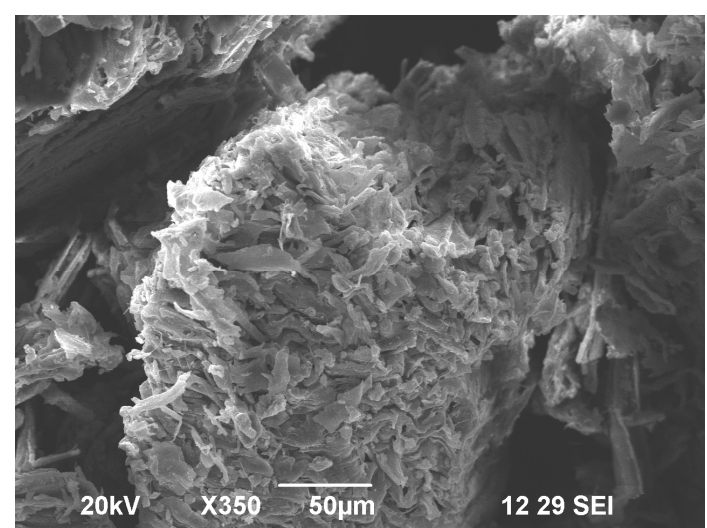

(a)

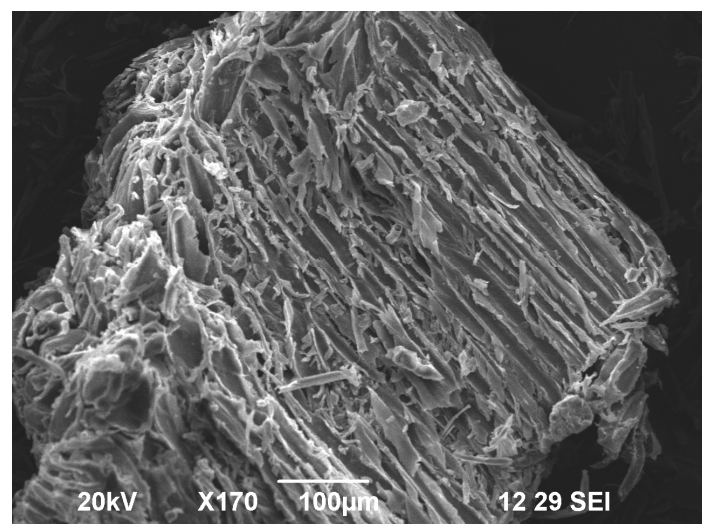

(b)

Figure 5. SEM images of (a) MRC and (b) ZRC.

the MRC and ZRC are presented in the Figures 6(a) and (b). The elements, percentage mass of elements presented in MRC and ZRC are summarized in Tables 3 and 4.

\subsection{Effect of Solution pH on MG Dye Adsorption}

The effect of solution $\mathrm{pH}$ is very important when the adsorbing molecules are capable of ionizing in response to the current $\mathrm{pH}$ [24]. The uptake of MG from aqueous solution was greatly affected by the variation of $\mathrm{pH}$ value, as shown in Figure 7. When the $\mathrm{pH}$ was lower than 3, the uptake went up sharply with the increase of $\mathrm{pH}$. The maximum $\mathrm{MG}$ uptake was obtained at $\mathrm{pH}=5$. At the initial dye concentration of $100 \mathrm{mg} / \mathrm{L}$, removal efficiency was $19.43 \%, 36.10 \%$ at a solution $\mathrm{pH}$ of 2.0 for MRC and ZRC, respectively, but it increased when solution $\mathrm{pH}$ increases from 2 to 5 . At $\mathrm{pH} 5$, the removal efficiency was $48.58 \%, 63.56 \%$ for MRC and ZRC, respectively.

The optimum $\mathrm{pH}$ value for the adsorption of $\mathrm{MG}$ onto MRC and ZRC ( $\mathrm{pH}=5)$ was observed. That may be attributed to the hydrophobic nature of the developed carbon which led to absorb hydrogen ions $\left(\mathrm{H}^{+}\right)$onto the surface of the carbon when immersed in water and make
Table 3. Data for the elements presented in MRC.

\begin{tabular}{cccccc}
\hline \multicolumn{2}{c}{ Element } & $(\mathrm{keV})$ & Mass \% & Atom \% & $\mathrm{K}$ \\
\hline $\mathrm{C}$ & $\mathrm{K}$ & 0.277 & 81.56 & 87.06 & 1 \\
$\mathrm{O}$ & $\mathrm{K}$ & 0.525 & 14.55 & 11.66 & 0.3805 \\
$\mathrm{~K}$ & $\mathrm{~K}$ & 3.312 & 3.89 & 1.28 & 0.4333 \\
\multicolumn{2}{c}{ Total } & & 100 & 100 & \\
\hline
\end{tabular}

Table 4. Data for the elements presented in ZRC.

\begin{tabular}{|c|c|c|c|c|}
\hline Element & $(\mathrm{keV})$ & Mass $\%$ & Atom \% & $\mathrm{K}$ \\
\hline C $\mathrm{K}$ & 0.277 & 76.02 & 84.53 & 1 \\
\hline K & 0.525 & 16.76 & 14 & 0.3805 \\
\hline $\mathrm{Zn} \mathrm{L}$ & 1.012 & 7.22 & 1.47 & 1.2304 \\
\hline Total & & 100 & 100 & \\
\hline
\end{tabular}

it positively charged. Low pH value (1.0 to 4.0$)$ leads to an increase in $\mathrm{H}^{+}$ion concentration in the system and the surface of the activated carbon acquires positive charge by absorbing $\mathrm{H}^{+}$ions. On the other hand, increase of the $\mathrm{pH}$ value led to increase of the number of negatively charged sites. As the adsorbent surface is negatively charged at high $\mathrm{pH}$, a significantly strong electrostatic attraction appears between the negatively charged carbon surface and cationic dye molecule leading to maximum adsorption of MG from waste water [28]. The lowest adsorption occurred at $\mathrm{pH} 2.0$ and the greatest adsorption occurred at $\mathrm{pH} \sim 5.0$. Adsorbents surface would be positively charged up to $\mathrm{pH}<4$, and heterogeneous in the $\mathrm{pH}$ range $4-5$, thereafter it should be negatively charged. Moreover, the increasing in the adsorption of dye with increasing of $\mathrm{pH}$ value is also due to the attraction between cationic dye and excess $\mathrm{OH}^{-}$ions in the solution [29]. When solution $\mathrm{pH}$ increases, high $\mathrm{OH}^{-}$ions accumulate on the adsorbent surface [30]. Therefore, electrostatic interaction between negatively charged adsorbent surface and cationic dye molecule caused the increase in adsorption. Furthermore, the solution $\mathrm{pH}$ is above the zero point of charge $\left(\mathrm{pH}_{\mathrm{zpc}}, 3.14\right.$ for $\mathrm{MRC}$ and $\mathrm{pH}_{\mathrm{zpc}}, 4.0$ for ZRC) and hence the negative charge density of the surface of the adsorbents were increased which favors the adsorption of cationic dye [22].

\subsection{Effect of Adsorbent Dose on MG Adsorption}

The adsorbent dose is an important parameter in adsorption studies because it determines the capacity of adsorbent for a given initial dye concentration of dye solution. The effect of adsorbent dose on MG dye removal percentage is shown in Figure 8. The effect of adsorbent dose was observed by keeping the optimum $\mathrm{pH}$ at equi- 


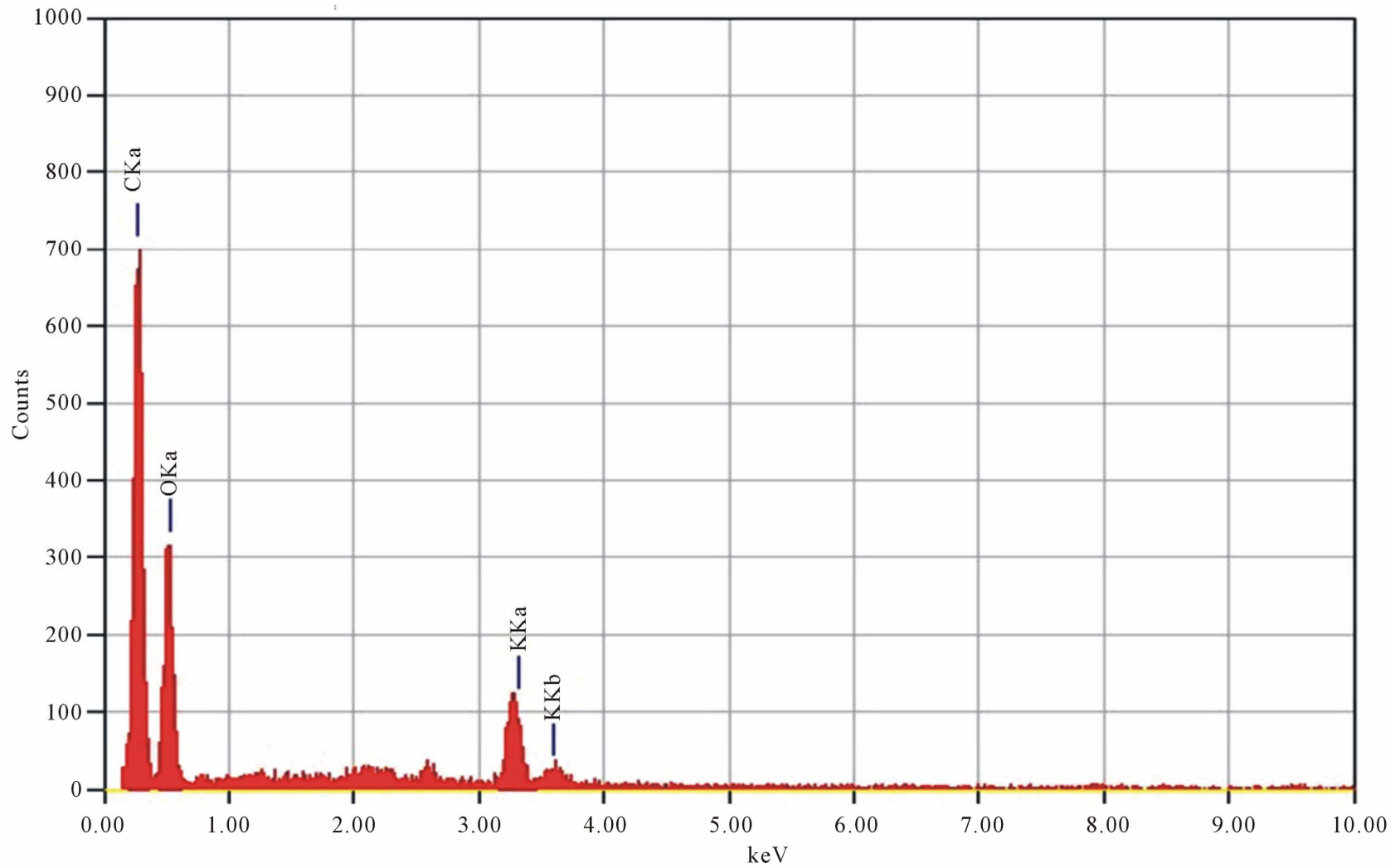

(a)

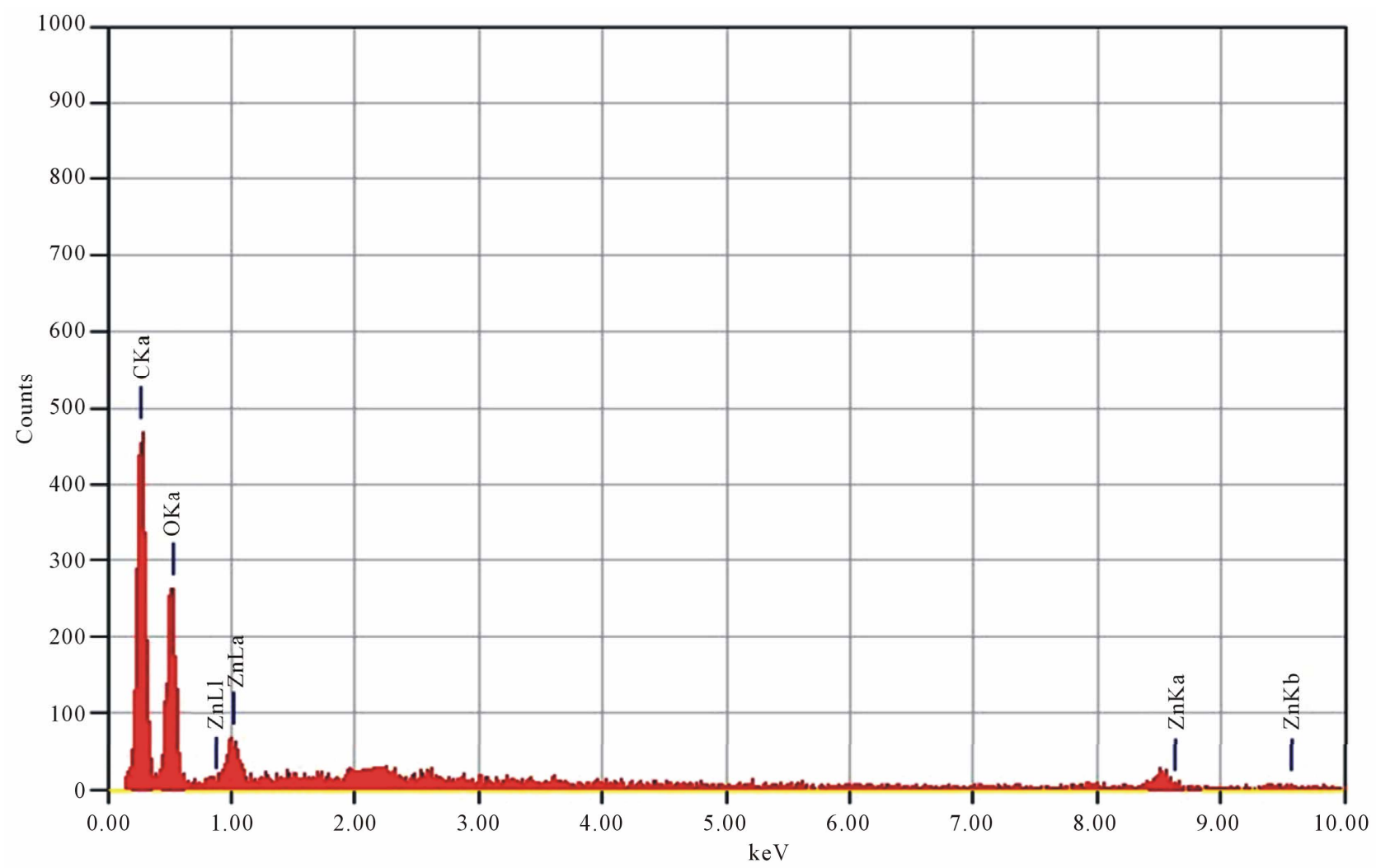

(b)

Figure 6. EDAX spectra of (a) MRC and (b) ZRC. 


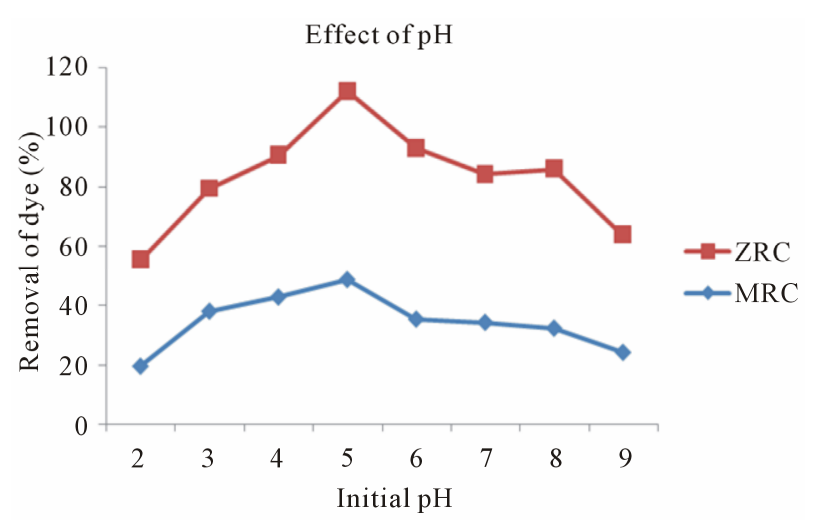

Figure 7. Effect of pH on the adsorption of MG onto MRC and ZRC.

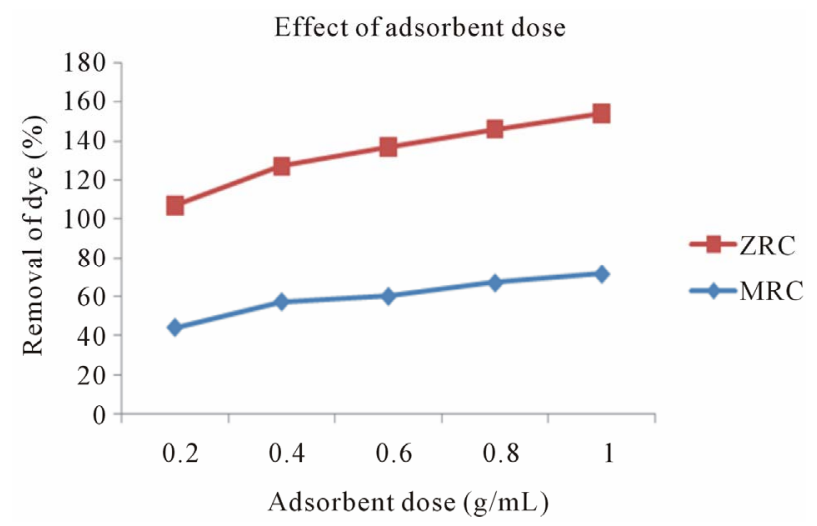

Figure 8. Effect of adsorbent dose on the removal of MG onto MRC and ZRC (MG concentration $100 \mathrm{mg} / \mathrm{L}$, contact time 2 h, solution pH 5).

librium times for each adsorption process. It was observed that the percentage of adsorption increases with increase in adsorbent dose from $0.2 \mathrm{~g}$ to $1 \mathrm{~g}$ in $\mathrm{MG}$ with the concentration of dye solution of $100 \mathrm{mg} / \mathrm{L}$. The increase in $\%$ dye removal was due to the increase of the available sorption surface and availability of adsorption sites [31]. A similar observation was previously reported for the removal of malachite green dye from aqueous solution by bagasse fly ash and activated carbon [32]. Therefore, $0.2 \mathrm{~g} / \mathrm{mL}$ of adsorbent was chosen for later studies on MG adsorption.

\subsection{Effect of Initial MG Dye Concentration}

The data for the uptake of MG onto MRC and ZRC as a function of initial dye concentration is presented in Figure 9. It can be seen (Figure 9) that the amount of MG adsorbed per unit mass of adsorbent increased with the increase in initial concentration and attained saturation after equilibrium time, although percentage removal decreased with the increase in initial concentration. The percentage removal shows that, with an increase in the initial concentration of dyes, the percent removal was

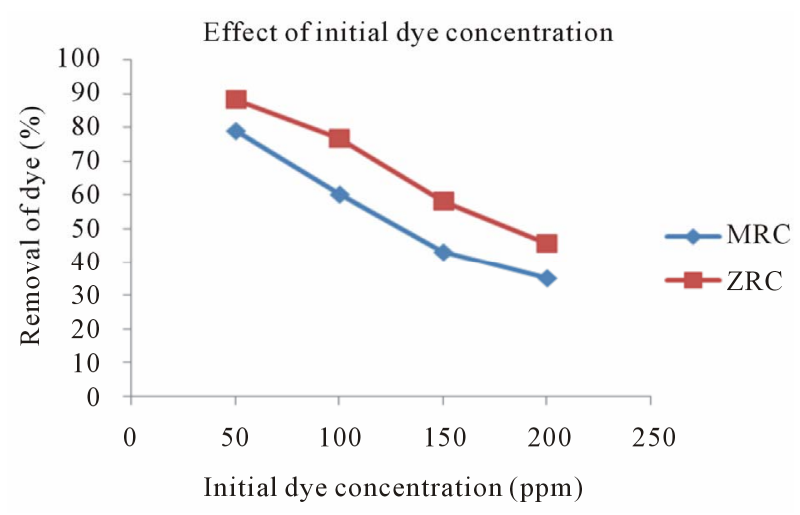

Figure 9. Effect of Initial dye concentration on the removal of MG onto MRC and ZRC (adsorbent dose $0.2 \mathrm{~g} / \mathrm{L}$, contact time 2 h, solution pH 5).

decreased from $79.10 \%$ to $35.04 \%$ (MG onto MRC), $88.24 \%$ to $55.60 \%$ (MG onto ZRC) for the dye concentration of 50 to $200 \mathrm{mg} / \mathrm{L}$.

This may be attributed to an increase in the driving force of the concentration gradient with increase in the initial dye concentration $[33,34]$.

\subsection{Adsorption Isotherm Studies for MG in Single System}

The Langmuir, Freundlich, Temkin and Dubinin-Radushkevich isotherm models were used to describe the relationship between the amount of MRC, ZRC adsorbed and its equilibrium concentration in solutions.

Langmuir [35] proposed a theory to describe the adsorption of gas molecules onto metal surfaces. The Langmuir adsorption isotherm has been successfully applied to many real sorption processes. Langmuir isotherm model assumes uniform energies of adsorption onto the surface without transmigration of adsorbate in the plane of the surface [36]. Therefore, the Langmuir isotherm model was chosen for the estimation of maximum adsorption capacity corresponding to complete monolayer coverage on the adsorbent surface. The Langmuir nonlinear equation is commonly expressed as:

$$
\mathrm{q}_{\mathrm{e}}=\frac{\mathrm{Q}_{\mathrm{m}} \mathrm{K}_{\mathrm{L}} \mathrm{C}_{\mathrm{e}}}{1+\mathrm{K}_{\mathrm{L}} \mathrm{C}_{\mathrm{e}}}
$$

In Equation (3), $\mathrm{C}_{\mathrm{e}}$ and $\mathrm{q}_{\mathrm{e}}$ are defined as before in Equation (2), $\mathrm{Q}_{\mathrm{m}}$ is a constant and reflect a complete monolayer coverage $(\mathrm{mg} / \mathrm{g}), \mathrm{K}_{\mathrm{L}}$ is adsorption equilibrium constant $(\mathrm{L} / \mathrm{mg})$ that is related to the apparent energy of sorption. Langmuir isotherm [37] assumes monolayer adsorption onto a surface containing a finite number of adsorption sites. The Langmuir isotherm Equation (3) can be linearized into the following form [38,39]:

$$
\frac{\mathrm{C}_{\mathrm{e}}}{\mathrm{q}_{\mathrm{e}}}=\frac{1}{\mathrm{~K}_{\mathrm{L}} \mathrm{Q}_{\mathrm{m}}}+\frac{1}{\mathrm{Q}_{\mathrm{m}}} \times \mathrm{C}_{\mathrm{e}}
$$


A plot of $\mathrm{C}_{\mathrm{e}} / \mathrm{q}_{\mathrm{e}}$ verses Ce should indicate a straight line slope of $1 / \mathrm{Q}_{\mathrm{m}}$ and an intercept of $1 / \mathrm{K}_{\mathrm{L}} \mathrm{Q}_{\mathrm{m}}$. Table 5 shows the values of the correlation coefficient $\left(\mathrm{R}^{2}\right)$, sorption capacity $\left(\mathrm{Q}_{\mathrm{m}}\right)$, and sorption energy (n) calculated from the plot indicated in Figure 10. The correlation coefficient $\left(\mathrm{R}^{2}\right)$ for the adsorption of MG onto MRC (S) and ZRC (S) is equal to 0.990 and 0.9960 , showing a favorable adsorption of MG onto MRC and ZRC in single system $(\mathrm{S})$.

The value of $\mathrm{Q}_{\mathrm{m}}$ obtained was equal to $12.65 \mathrm{mg} / \mathrm{g}$ and $24.39 \mathrm{mg} / \mathrm{g}$ for MRC (S) and ZRC (S), indicating a very strong monolayer adsorption of the adsorbate on the surface.

The Freundlich isotherm is an empirical equation assuming that the adsorption process takes place on a heterogeneous surface through a multilayer adsorption mechanism and adsorption capacity is related to the concentration of dye at equilibrium [40]. The Freundlich equation is given as:

$$
\mathrm{q}_{\mathrm{e}}=\mathrm{K}_{\mathrm{f}} \mathrm{C}_{\mathrm{e}}^{1 / \mathrm{n}}
$$

where $\mathrm{q}_{\mathrm{e}}$ is the amount of adsorbate at equilibrium $(\mathrm{mg} / \mathrm{g}), \mathrm{C}_{\mathrm{e}}$ is the equilibrium concentration of the adsorbate $(\mathrm{mg} / \mathrm{L}), \mathrm{K}_{\mathrm{f}}$ is the Freundlich adsorption constant

Table 5. Adsorption isotherm parameters of MG in single and binary system.

\begin{tabular}{|c|c|c|c|c|}
\hline Isotherm model & $\mathrm{MRC}(\mathrm{S})$ & $\operatorname{MRC}(B)$ & $\mathrm{ZRC}(\mathrm{S})$ & $\mathrm{ZRC}(\mathrm{B})$ \\
\hline \multicolumn{5}{|l|}{ Langmuir } \\
\hline $\mathrm{Q}_{\mathrm{m}}\left(\mathrm{mg} \cdot \mathrm{g}^{-1}\right)$ & 12.6500 & 11.7647 & 24.3900 & 20.4081 \\
\hline $\mathrm{b}\left(\mathrm{L} \cdot \mathrm{mg}^{-1}\right)$ & 0.2041 & 0.0850 & 0.0073 & 0.0491 \\
\hline $\mathrm{R}^{2}$ & 0.9900 & 0.9800 & 0.9960 & 0.9790 \\
\hline \multicolumn{5}{|l|}{ Freundlich } \\
\hline $1 / \mathrm{n}$ & 0.0590 & 0.3570 & 0.2820 & 0.3740 \\
\hline $\mathrm{K}_{\mathrm{f}}\left(\mathrm{mg} \cdot \mathrm{g}^{-1}\right)$ & 8.9000 & 3.7325 & 5.9000 & 2.2542 \\
\hline $\mathrm{R}^{2}$ & 0.8860 & 0.9140 & 0.9780 & 0.9690 \\
\hline \multicolumn{5}{|l|}{ Dubinin-Radushkevich } \\
\hline $\mathrm{Q}_{\mathrm{m}}\left(\mathrm{mg} \cdot \mathrm{g}^{-1}\right)$ & 11.7230 & 10.6400 & 19.8000 & 18.177 \\
\hline $\mathrm{K}\left(\times 10^{-5} \mathrm{~mol}^{2} \cdot \mathrm{kJ}^{-2}\right)$ & 1.0000 & 2.0000 & 1.0000 & 1.0000 \\
\hline $\mathrm{E}\left(\mathrm{kJ} \cdot \mathrm{mol}^{-1}\right)$ & 0.0709 & 0.1581 & 0.0707 & 1.0000 \\
\hline $\mathrm{R}^{2}$ & 0.6390 & 0.9370 & 0.8350 & 0.9600 \\
\hline \multicolumn{5}{|l|}{ Temkin } \\
\hline$\alpha\left(\mathrm{Lg}^{-1}\right)$ & 3.2060 & 0.1191 & 2.6050 & 0.3112 \\
\hline$\beta\left(\mathrm{mg} \cdot \mathrm{L}^{-1}\right)$ & 0.6660 & 4.7280 & 4.3420 & 0.7370 \\
\hline $\mathrm{b}$ & 349.53 & 52.7530 & 53.614 & 235.58 \\
\hline $\mathrm{R}^{2}$ & 0.8690 & 0.9400 & 0.9890 & 0.9590 \\
\hline
\end{tabular}

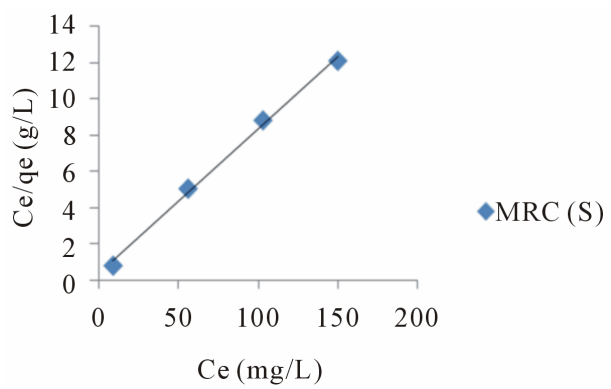

(a)

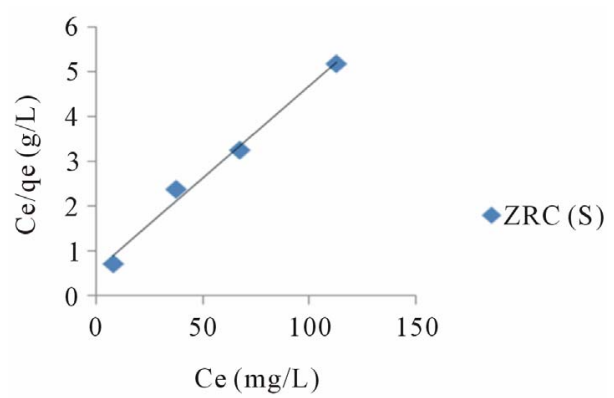

(b)

Figure 10. Langmuir adsorption isotherm for MG onto (a) S-MRC and (b) S-ZRC.

related to adsorption capacity of the adsorbent and $1 / \mathrm{n}$ is the adsorption intensity. A linear form of the Freundlich equation is generally expressed as follows:

$$
\ln \mathrm{q}_{\mathrm{e}}=\ln \mathrm{K}_{\mathrm{f}}+\frac{1}{\mathrm{n}} \ln \mathrm{C}_{\mathrm{e}}
$$

The values of $K_{f}$ and $1 / n$ were calculated from the intercept and slope of the plot of $\ln \mathrm{q}_{\mathrm{e}}$ versus $\ln \mathrm{C}_{\mathrm{e}}$. Table 5 shows the calculated Freundlich parameters. The coefficient $\mathrm{K}_{\mathrm{f}}$, correlation coefficient $\left(\mathrm{R}^{2}\right)$ was slightly less than that of Langmuir isotherm and, consequently, was a less favorable adsorption.

The Dubinin-Radushkevich equation can be expressed [41] as:

$$
\mathrm{q}_{\mathrm{e}}=\mathrm{q}_{\mathrm{m}} \mathrm{e}^{-\mathrm{K}^{\prime} \varepsilon^{2}}
$$

where $\varepsilon$ (Polanyi potential) is equal to RT $\ln \left(1+1 / \mathrm{C}_{\mathrm{e}}\right)$, $\mathrm{q}_{\mathrm{e}}$ is the amount of the dye adsorbed per unit activated carbon $(\mathrm{mol} / \mathrm{g}), \mathrm{q}_{\mathrm{m}}$ the theoretical monolayer saturation capacity $(\mathrm{mol} / \mathrm{g}), \mathrm{C}_{\mathrm{e}}$ the equilibrium concentration of the dye solution $(\mathrm{mol} / \mathrm{L}), \mathrm{K}^{\prime}$ is the constant of the adsorption energy $\left(\mathrm{mol}^{2} / \mathrm{kJ}^{2}\right), \mathrm{R}$ is the gas constant $(8.314 \mathrm{KJ} / \mathrm{mol} \mathrm{K})$, and $T$ is the temperature $(K)$. The linear form of the $D-R$ isotherm is:

$$
\ln \mathrm{q}_{\mathrm{e}}=\ln \mathrm{q}_{\mathrm{m}}-\mathrm{k}^{\prime} \varepsilon^{2}
$$
[42]:

$\mathrm{K}^{\prime}$ is related to mean adsorption energy $\mathrm{E}(\mathrm{kJ} / \mathrm{mol})$ as

$$
\mathrm{E}=\frac{1}{\sqrt{2 \mathrm{~K}^{-1}}}
$$


The calculated D-R adsorption isotherm parameters should be summarized in Table 5 .

Temkin and Pyzhev considered the effects of some indirect sorbate/adsorbate interactions on adsorption isotherms, and suggest that the heat of adsorption of all the molecules in the layer would decrease linearly with coverage due to these interactions [43]. The Temkin isotherm has been used in the following form:

$$
\mathrm{q}_{\mathrm{e}}=\frac{\mathrm{RT}}{\mathrm{b}} \ln \left(\mathrm{K}_{\mathrm{T}} \mathrm{C}_{\mathrm{e}}\right)
$$

where $\mathrm{K}_{\mathrm{T}}$ is the equilibrium binding constant $(\mathrm{L} / \mathrm{g})$, $\mathrm{b}$ is related to heat of adsorption $(\mathrm{J} / \mathrm{mol}), \mathrm{R}$ is the universal gas constant $(8.314 \mathrm{~J} / \mathrm{mol} \mathrm{K})$ and $\mathrm{T}$ is the absolute temperature (K). Equation (10) can be written as the following form:

$$
\mathrm{q}_{\mathrm{e}}=\mathrm{B}_{1} \ln \left(\mathrm{K}_{\mathrm{T}} \mathrm{C}_{\mathrm{e}}\right)
$$

The Temkin adsorption isotherm parameters are calculated and the values are summarized in Table 5.

Adsorption isotherms describe the interaction of adsorbates with the adsorbent materials, and thus are critical for optimization of the adsorption mechanism pathways [44]. Therefore, the correlation of equilibrium data by the empirical equations is essential to the practical design and operation of adsorption systems [45]. The experimental data of MG dye were modeled using Langmuir, Freundlich, Temkin and Dubinin-Radushkevich isotherm models. Isotherm parameters for the adsorption of MG onto MRC and ZRC in single (S) and binary system (B) were summarized in Table 5. The applicability of Langmuir isotherm model suggests that the adsorption takes place on homogeneous sites within the adsorption site (the adsorbed layer is one molecule in thickness), with each molecule possess constant enthalpies and sorption activation energy. The results also demonstrate there is no interaction and transmigration of dyes in the plane of the neighboring surface.

\subsection{Adsorption Kinetics}

The kinetics describes the rate of adsorbate uptake on activated carbon. In order to identify the potential rate controlling steps involved in the process of adsorption, four kinetic models were studied and used to fit the experimental data from the adsorption of MG dye onto MRC and ZRC. These models are the pseudo-first-order, pseudo-second-order, Elovich and intra-particle kinetic models.

\subsubsection{Pseudo-First-Order Kinetic Model}

The pseudo first-first-order equation of Lagergren is generally expressed as follows [46,47]:

$$
\frac{\mathrm{dq}_{\mathrm{t}}}{\mathrm{dt}}=\mathrm{K}_{1}\left(\mathrm{q}_{\mathrm{e}}-\mathrm{q}_{\mathrm{t}}\right)
$$

After integration and applying boundary conditions, $\mathrm{t}=0$ to $\mathrm{t}=\mathrm{t}$ and $\mathrm{q}_{\mathrm{t}}=0$ to $\mathrm{q}_{\mathrm{t}}=\mathrm{qt}$; the integrated form of the above equation becomes:

$$
\mathrm{q}_{\mathrm{t}}=\mathrm{q}_{\mathrm{e}}\left(1-\mathrm{e}^{-\mathrm{K}_{1} \mathrm{t}}\right)
$$

However, Equation (13) is transformed into its linear form for use in the kinetic analyses of data can be expressed as:

$$
\ln \left(\mathrm{q}_{\mathrm{e}}-\mathrm{q}_{\mathrm{t}}\right)=\ln \mathrm{q}_{\mathrm{e}}-\mathrm{K}_{1} \mathrm{t}
$$

where $\mathrm{q}_{\mathrm{e}}(\mathrm{mg} / \mathrm{g})$ and $\mathrm{q}_{\mathrm{t}}(\mathrm{mg} / \mathrm{g})$ are the amount of adsorbed adsorbate at equilibrium and at time $t$, respectively, and $\mathrm{k}_{1}(1 / \mathrm{min})$ is the rate constant of pseudo firstorder adsorption. The straight line plots of $\log \left(\mathrm{q}_{\mathrm{e}}-\mathrm{q}_{\mathrm{t}}\right)$ against $t$ of Equation (14) were made.

The data for the pseudo-first-order kinetic model of MG onto MRC (S) and ZRC (S) are summarized in Table 6. In order to obtain the rate constants, the values of $\log \left(\mathrm{q}_{\mathrm{e}}-\mathrm{q}_{\mathrm{t}}\right)$ were linearly correlated with time. The plot of $\log \left(q_{e}-q_{t}\right)$ versus time gives a linear relationship from which $\mathrm{k}_{1}$ and predicted $\mathrm{q}_{\mathrm{e}}$ can be determined from the slope and intercept of the plot. The $\mathrm{K}_{1}$ values, correlation coefficient values and $\mathrm{q}_{\mathrm{e}}$ values (experimental and calculated) are summarized in Table 6. The correlation coefficient $\mathrm{R}^{2}$ is relatively low for the adsorption data. Besides, the experimental $\mathrm{q}_{\mathrm{e}}$ values, did not agree with the calculated values obtained from the linear plots. It suggests that the kinetics of MG onto MRC and ZRC did not follow the pseudo-first-order kinetic model.

\subsubsection{Pseudo-Second-Order Kinetic Model}

The rate of sorption is a second-order mechanism, the pseudo-second-order chemisorptions kinetic rate equation is expressed as:

$$
\frac{\mathrm{t}}{\mathrm{q}_{\mathrm{t}}}=\frac{1}{\mathrm{Kq}_{\mathrm{e}}^{2}}+\frac{1}{\mathrm{q}_{\mathrm{e}}} \mathrm{t}
$$

where $\mathrm{q}_{\mathrm{e}}$ and $\mathrm{q}_{\mathrm{t}}$ are the sorption capacities at equilibrium and at time $\mathrm{t}$, respectively $(\mathrm{mg} / \mathrm{g})$ and $\mathrm{k}$ is the rate constant of pseudo-second-order sorption $(\mathrm{g} / \mathrm{mg} / \mathrm{min})$. Where $\mathrm{h}$ can be regarded as the initial sorption rate as $\mathrm{q}_{\mathrm{t}} / \mathrm{t}$ tents to zero, hence:

$$
\mathrm{h}=\mathrm{kq}_{\mathrm{e}}^{2}
$$

Equation (16) can be written as:

$$
\frac{\mathrm{t}}{\mathrm{q}_{\mathrm{t}}}=\frac{1}{\mathrm{~h}}+\frac{1}{\mathrm{q}_{\mathrm{e}}} \times \mathrm{t}
$$

Equation (16) does not have the disadvantage of the problem with assigning an effective $\mathrm{q}_{\mathrm{e}}$. If Pseudo-second-order kinetics are applicable, the plot of $t / q_{t}$ against $t$ of Equation (17) should give a linear relationship, from which $\mathrm{q}_{\mathrm{e}}, \mathrm{k}$ and $\mathrm{h}$ can be determined from the slope and intercept of the plot (Figure 11) and there is no need to 
Table 6. Comparision of the correlation coefficients of kinetic parameters for MG adsorption onto MRC and ZRC in single and binary system.

\begin{tabular}{|c|c|c|c|c|c|}
\hline Models & Parameters & $\operatorname{MRC}(\mathrm{S})$ & ZRC (S) & $\operatorname{MRC}(\mathrm{B})$ & ZRC (B) \\
\hline \multirow{3}{*}{ Pseudo first-order model } & $\mathrm{k}_{1}\left(\min ^{-1}\right)$ & 0.0492 & 0.0382 & 0.0391 & 0.0420 \\
\hline & $\mathrm{q}_{\mathrm{e}}(\mathrm{mg} / \mathrm{g})$ & 14.4565 & 28.913 & 4.6558 & 5.6720 \\
\hline & $\mathrm{R}^{2}$ & 0.7700 & 0.8713 & 0.9350 & 0.9180 \\
\hline \multirow{4}{*}{ Pseudo second-order model } & $\mathrm{k}_{2}(\mathrm{~g} / \mathrm{mg} / \mathrm{min})$ & 0.0671 & 0.0593 & 0.0085 & 7.9103 \\
\hline & $\mathrm{q}_{\mathrm{e}}(\mathrm{mg} / \mathrm{g})$ & 11.9047 & 23.8095 & 9.9047 & 11.3457 \\
\hline & $\mathrm{h}$ & 2.1400 & 0.9963 & 13.6979 & 4.4840 \\
\hline & $\mathrm{R}^{2}$ & 0.9900 & 0.9967 & 0.9620 & 0.9870 \\
\hline \multirow{3}{*}{ Intra particle diffusion model } & $\mathrm{k}_{\mathrm{dif}}\left(\mathrm{mg} /\left(\mathrm{g} \cdot \min ^{1 / 2}\right)\right)$ & 1.0354 & 2.5882 & 0.0650 & 0.5750 \\
\hline & $\mathrm{C}$ & 4.2120 & 8.1679 & 0.1500 & 15.6400 \\
\hline & $\mathrm{R}^{2}$ & 0.8389 & 0.9862 & 0.9830 & 0.9260 \\
\hline \multirow{3}{*}{ Elovich model } & $\mathrm{A}_{\mathrm{E}}(\mathrm{mg}(\mathrm{g} / \mathrm{min}))$ & 0.4310 & 0.1660 & 5.4645 & 1.7636 \\
\hline & $\mathrm{b}(\mathrm{g} / \mathrm{mg})$ & 0.2004 & 0.1979 & 2.5616 & 7.5863 \\
\hline & $\mathrm{R}^{2}$ & 0.9380 & 0.8154 & 0.6410 & 0.5640 \\
\hline
\end{tabular}

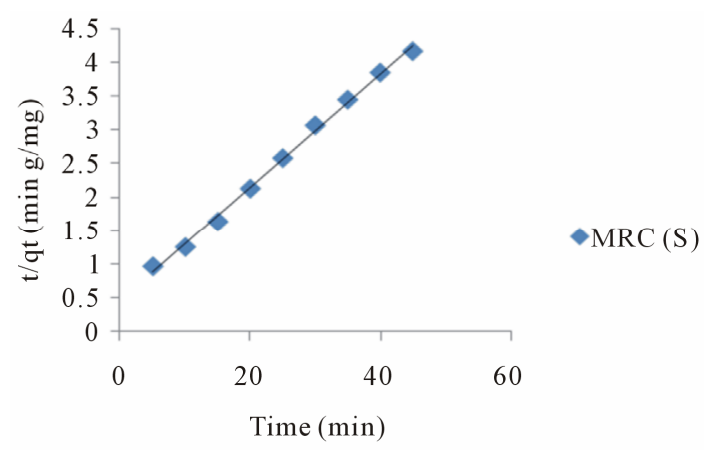

(a)

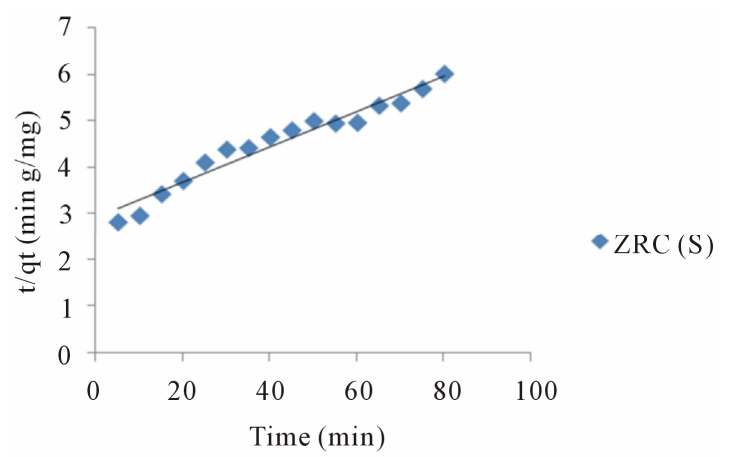

(b)

Figure 11. Pseudo-second-order kinetics for the adsorption of MG onto (a) S-MRC and (b) S-ZRC.

know any parameter. The $\mathrm{q}_{\mathrm{e}}$ and $\mathrm{k}_{2}$ values were estimated from the slope $\left(1 / \mathrm{q}_{\mathrm{e}}\right)$ and intercept $\left(1 / \mathrm{k}_{2} \mathrm{q}_{\mathrm{e}}^{2}\right)$ of linear plot of $\mathrm{t} / \mathrm{q}_{\mathrm{t}}$ verses $\mathrm{t}$.

The data for the pseudo-second-order kinetic model of
MG onto MRC (S) and ZRC (S) are summarized in Table 6 . The corresponding correlation coefficient $\left(\mathrm{R}^{2}\right)$ values for the pseudo-second-order kinetic model were 0.9900 for MRC (S) and 0.9967 for ZRC (S), respectively, indicates the applicability of the pseudo-secondorder kinetic model to describe the adsorption process of MG onto MRC and ZRC. This led to believe that the pseudo-second-order kinetic model provided good correlation for the adsorption. The higher $\mathrm{R}^{2}$ values confirm that the sorption process of dyes onto MRC and ZRC follow a pseudo-second-order kinetic model. Similar trends were observed for dye adsorption onto Zea mays (maize) cob [48], for adsorption onto ginger waste [30]. It suggested that the adsorption process was controlled by chemisorption process [31].

\subsubsection{Intra Particle Diffusion Model}

The adsorption of MG dye onto MRC (S) and ZRC (S) may be controlled by via external flim diffusion at earlier stages and later by the particle diffusion. The possibility of intra particle diffusion resistance was identified by using the following intra particle diffusion model as [49]:

$$
\mathrm{q}_{\mathrm{t}}=\mathrm{K}_{\text {dif }} \mathrm{t}^{1 / 2}+\mathrm{C}
$$

where $K_{\text {dif }}$ is the intra-particle diffusion rate constant $\left(\mathrm{mg} /\left(\mathrm{g} \cdot \mathrm{min}^{1 / 2}\right), \mathrm{C}\right.$ is the intercept. The values of $\mathrm{q}_{\mathrm{t}}$ correlated linearly with the values of $\mathrm{t}^{1 / 2}$ and the rate constant $\mathrm{K}_{\text {dif }}$ directly evaluated from the slope of regression line. The data for the intra-particle kinetic model of MG onto MRC (S) and ZRC (S) are summarized in Table 6.

The linearity of the plots demonstrated that intra-par- 
ticle diffusion played a significant role in the uptake of the MG onto MRC and ZRC. However, as still there is no sufficient indication about it, Ho [50] has shown that if the intra-particle diffusion is the sole rate-limiting step, it is essential for the qt versus $t^{1 / 2}$ plots to pass through the origin, which is not the case, it may be concluded that surface adsorption and intra-particle diffusion were concurrently operating during the MRC and ZRC interactions. Hence intra-particle diffusion is not a fully operative mechanism in the sorption of MG onto MRC and ZRC.

\subsubsection{Elovich Kinetics}

The Elovich kinetic is another rate equation based on the adsorption capacity generally expressed as follows:

$$
\frac{d q_{t}}{d t}=B_{E} e^{-\left(A_{E} q_{t}\right)}
$$

where $B_{E}$ is the initial adsorption rate constant (mg $(\mathrm{g} / \mathrm{min})$ and $\mathrm{A}_{\mathrm{E}}$ is the desorption constant $(\mathrm{g} / \mathrm{mg})$ during any experiment.

It is simplified by assuming $A_{E} B_{E} t \gg t$ and by applying the boundary conditions $\mathrm{q}_{\mathrm{t}}=0$ at $\mathrm{t}=0$ and $\mathrm{q}_{\mathrm{t}}=\mathrm{t}$ at $\mathrm{t}=\mathrm{t}$ above Equation (19) becomes:

$$
\mathrm{q}_{\mathrm{t}}=\frac{1}{\mathrm{~A}_{\mathrm{E}}}\left(\mathrm{B}_{\mathrm{E}} \mathrm{A}_{\mathrm{E}}\right)+\frac{1}{\mathrm{~A}_{\mathrm{E}}} \ln \mathrm{t}
$$

If $M G$ adsorption by MRC and ZRC fits the Elovich model, a plot of $q_{t}$ versus $\ln (t)$ should yield a linear relationship with a slope of $\left(1 / \mathrm{A}_{\mathrm{E}}\right)$ and an intercept of $\left(1 / \mathrm{A}_{\mathrm{E}}\right)$ $\ln \left(A_{E} B_{E}\right)$. Thus the constants can be obtained from the slope and the intercept of the straight line.

Thus, the constants can be obtained from the slope and the intercept are shown in Table 6. The parameter $1 / A_{E}$ is related to the number of sites available for adsorption while $\left(1 / A_{E}\right) \ln \left(A_{E} B_{E}\right)$ is the adsorption quantity when $\ln$ $t$ is equal to zero; ie, the adsorption quantity when $t$ is 1 min. This value is helpful in understanding the adsorption behavior of the first step [51]. In the case of using the Elovich equation, the correlation coefficients are lower than those of pseudo-second-order equation. The Elovich equation does not predict any definite mechanism, but it is useful in describing adsorption on highly heterogeneous adsorbents.

The correlation coeffecients obtained for the pseudosecond-order kinetic model are greater than 0.93 for MRC (S) and ZRC (S). The theoretical $\mathrm{q}_{\mathrm{t}}$ values of the pseudo-second-order kinetic model for MRC (S) and ZRC (S) are close to the experimental values than those of the other models. The pseudo-second-order kinetic model fits the experimental data better than the other kinetic models in this study.

The Langmuir isotherm and pseudo-second-order kinetic model provide best correlation with the experimen- tal data for the adsorption of MG onto MRC and ZRC for different initial dye concentrations over the whole range studied. Both Langmuir isotherm and pseudo-secondorder kinetic model assumes that the MRC and ZRC surface is homogenous and the operating adsorption mechanism is chemisorptions process.

\subsection{The Competitive Adsorption of MG in Binary System}

Effects of the presence of MRC and ZRC on the adsorption of MG were investigated in terms of equilibrium isotherm and adsorption kinetics. A comparison of the adsorbed quantity of MG onto MRC and ZRC in single system at equilibrium between the solutions with $\mathrm{MG}$ present in the binary system (B) was given in Figure 12. As shown in Figure 12, the results indicated that the equilibrium uptake of MG onto MRC and ZRC in single and binary systems.

All the correlation coefficient, $\mathrm{R}^{2}$ values and the constants obtained from the four isotherm models and four kinetic models are summarized in Tables 5 and $\mathbf{6}$. The Langmuir isotherm model gave the highest $\mathrm{R}^{2}$ values. Among the four kinetic models pseudo-second-order model fits well for MG adsorption onto MRC and ZRC in single and binary system. In the single dye solution, the maximum uptake obtained at initial concentrations of MG $100 \mathrm{mg} / \mathrm{L}, \mathrm{pH} 5$ was found to be $12.65 \mathrm{mg} / \mathrm{g}$ for MRC (S) and $24.39 \mathrm{mg} / \mathrm{g}$ for ZRC (S), while the uptake obtained in the binary solutions at the same initial dye concentration of $\mathrm{MG}$ and adsorption conditions, was found to be $11.764 \mathrm{mg} / \mathrm{g}$ for MRC (B) and $20.4081 \mathrm{mg} / \mathrm{g}$ for ZRC (B), respectively.

A fixed quantity of MG onto MRC (S) and ZRC (S) could only offer a finite number of surface binding sites, some of which would be expected to be saturated by the competing dye solutions. The decrease in sorption capacity of same activated carbon in target dye solution than that of single (S) dye may be ascribed to the less availability of binding sites. In case of binary dye (B) solution,

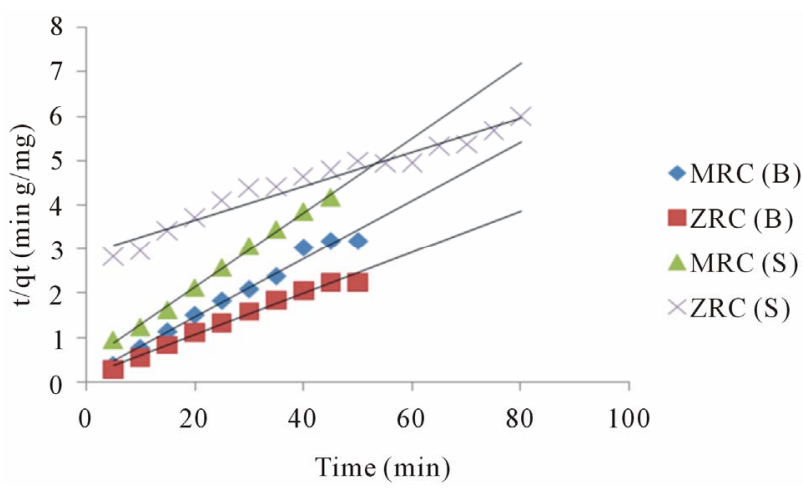

Figure 12. Comparision of pseudo-second-order kinetics of MG in single and binary solutions onto MRC and ZRC. 
the binding site is competitively divided among the various dye solutions.

Among MRC and ZRC, ZRC shows most adsorption ability than MRC in single system only onto MG adsorption from waste water using epicarp of Ricinus communis.

\section{Conclusion}

It had indicated that $\mathrm{ZnCl}_{2}$ was a suitable activating agent for the preparation of activated carbon from epicarp of Ricinus communis by microwave radiation. The effects of the impregnation ratio of $\mathrm{ZnCl}_{2}$, microwave radiation power and microwave radiation time and impregnation time on the yield and iodine number of ZRC were investigated systematically. The optimum conditions were microwave power of $100 \mathrm{~W}$, microwave radiation time of 4 min, concentration of zinc chloride of $30 \%$ by volume and impregnation time of $16 \mathrm{~h}$. SEM micrographs showed that the external surface of the chemically activated carbon was full of cavities compared with untreated Ricinus communis. The activated carbon prepared could effectively used as adsorbent for the removal of basic dye from aqueous solutions. Adsorption was found to be maximum in the $\mathrm{pH}$ of 5. Langmuir isotherm models given were fitting better than Freundlich, Temkin and Dubinin-Radushkevich isotherms interpreting the adsorption phenomenon of MG. MG adsorption system follows pseudo-second-order kinetic model, based on the assumption that the rate-limiting step may be chemisorptions process. MG adsorption rate onto MRC and ZRC was greater in single system (S) than in binary system (B) due to the competitive adsorption of dye onto the active site of the activated carbon. Among MRC and ZRC, ZRC shows most adsorption ability than MRC in single and binary system.

\section{REFERENCES}

[1] S. M. A. G. U. de Souza, L. C. Peruzzo and A. A. U. de Souza, "Numerical Study of the Adsorption of Dyes from Effluents," Applied Mathematical Modelling, Vol. 32, No. 9, 2008, pp. 1711-1718. doi:10.1016/j.apm.2007.06.007

[2] K. V. Kumar, S. Sivanesan and V. Ramamurthi, “Adsorption of Malachite Green onto Pithopora sp., a Fresh Water Algal: Equilibrium and Kinetic Modeling," Process Biochemistry, Vol. 40, No. 48, 2005, pp. 2865-2872. doi:10.1016/i.procbio.2005.01.007

[3] V. K. Gupta, A. Mittal, L. Krishnan and V. Gajbe, "Adsorption Kinetics and Column Operations for the Removal and Recovery of Malachite Green from Wastewater Using Bottom Ash," Separation and Purification Technology, Vol. 40, No. 1, 2004, pp. 87-96. doi:10.1016/j.seppur.2004.01.008

[4] M.-S. Chiou and H.-Y. Li, "Equilibrium and Kinetic Modeling of Adsorption of Reactive Dyes on Cross-Linked chitosan Beads," Journal of Hazardous Materials, Vol. 93, No. 2, 2002, pp. 233-248. doi:10.1016/S0304-3894(02)00030-4

[5] O. S. Bello, M. A. Ahmad and T. S. Tan, "Utilization of Cocoapod Husk for the Removal of Remazol Black B Reactive Dye from Aqueous Solutions: Kinetic, Equilibrium and Thermodynamic Studies," Trends in Applied Sciences Research, Vol. 6, No. 8, 2011, pp. 794-812. doi:10.3923/tasr.2011.794.812

[6] B. H. Hameed, A. L. Ahmad and K. N. A. Latiff, "Adsorption of Basic Dye (Methylene Blue) onto Activated Carbon Prepared from Rattan Sawdust," Dyes and Pigments, Vol. 75, No. 1, 2007, pp. 143-149.

doi:10.1016/j.dyepig.2006.05.039

[7] U. Kumar and M. Bandyopadhyay, "Sorption of Cadmium from Aqueous Solution Using Pretreated Rice Husk," Bioresource Technology, Vol. 97, No. 1, 2006, pp. 104-109. doi:10.1016/j.biortech.2005.02.027

[8] K. V. Kumar, "Optimum Sorption Isotherm by Linear and Nonlinear Methods for Malachite onto Lemon Peel," Dyes and Pigments, Vol. 74, No. 3, 2007, pp. 595-597. doi:10.1016/j.dyepig.2006.03.026

[9] R. M. Gong, X. P. Zhang, H. J. Liu, Y. Z. Sun and B. R. Liu, "Uptake of Cationic Dyes from Aqueous Solution by Biosorption onto Granular Kohlrabi Peel," Bioresource Technology, Vol. 98, No. 6, 2007, pp. 1319-1323. doi:10.1016/j.biortech.2006.04.034

[10] S. Senthilkumaar, P. R. Varadarajan, K. Porkodi and C. V. Subhuraam, "Adsorption of Methylene Blue onto Jute Fibre Carbon; Kinetics and Equilibrium Studies," Journal of Colloid and Interface Science, Vol. 284, No. 1, 2005, pp. 78-82. doi:10.1016/j.jcis.2004.09.027

[11] I. A. W.Tan, L. Ahmad and B. H. Hameed, "Optimization of Preparation Conditions for Activated Carbons from Coconut Husk Using Response Surface Methodology," Journal of Chemical Engineering, Vol. 137, No. 3, 2008, pp. 462-470. doi:10.1016/j.cej.2007.04.031

[12] J. Hayashi, A. Kazehaya, K. Muroyamo and A. P. Watkinson, "Preparation of Activated Carbon from Lignin by Chemical Activation," Carbon, Vol. 38, No. 13, 2008, pp. 1873-1878. doi:10.1016/S0008-6223(00)00027-0

[13] M. M. Karim, A. K. Das and S. H. Lee, "Treatment of Colored Effluent of the Textile Industry in Bangladesh Using Zinc Chloride Treated Indigenous Activated Carbons," Journal of Analtica Chimica Acta, Vol. 576, No. 1, 2006, pp. 37-42. doi:10.1016/j.aca.2006.01.079

[14] C. Almansa, M. Molina-Sabio and F. Rodruguez-Reinso, "Adsorption of Methane into $\mathrm{ZnCl}_{2}$-Activated Carbon Derived Discs," Journal of Microporous and Mesporous Materials, Vol. 76, No. 1-3, 2004, pp. 185-191. doi:10.1016/j.micromeso.2004.08.010

[15] W. Li, L.-B. Zhang, J.-H. Peng, N. Li and X.-Y. Zhang, "Preparation of High Surface Area Activated Carbons from Tobacco Stems with $\mathrm{K}_{2} \mathrm{CO}_{3}$ Activation Using Microwave Radiation," Journal of Industrial Crops and Products, Vol. 27, No. 3, 2008, pp. 341-347. doi:10.1016/j.indcrop.2007.11.011

[16] C. O. Ania, J. B. Parra, J. A. Menendez and J. J. Pis, "Ef- 
fect of Microwave and Conventional Regeneration on the Microporous and Mesporous Network on the Adsorptive Capacity of Activated Carbons," Journal of Microporous and Mesoporus Materials, Vol. 63, No. 1-2, 2005, pp. 7-15. doi:10.1016/j.micromeso.2005.06.013

[17] J. M. V. Nabais, P. J. M. Carrot, M. M. L. R. Carrott and J. A. Menendez, "Preparation and Modification of Activated Carbon Fibres by Microwave Heating," Carbon, Vol. 42, No. 7, 2004, pp. 1315-1320. doi:10.1016/j.carbon.2004.01.033

[18] D. A. Jones, T. P. Leyveld, S. D. Mavrofidis, S. W. Kingman and N. J. Miles, "Microwave Heating Applications in Environmental Engineering: A Review," Resources, Conservation and Recycling, Vol. 34, No. 2, 2002, pp. 75-90. doi:10.1016/S0921-3449(01)00088-X

[19] T. Santhi, S. Manonmani and T.Smitha, "The Removal of Malachite Green from Aqueous Solution by Activated Carbon Prepared from the Epicarp of Ricinus Communis by Adsorption," Journal of Hazardous Materials, Vol. 179, No. 1-3, 2010, pp. 178-186. doi:10.1016/j.jhazmat.2010.02.076

[20] A. Kumar, B. Prasad and I. M. Mishra, "Adsorptive Removal of Acryloinitrile by Commercial Grade Activated Carbon: Kinetics, Equilibrium and Thermodynamics," Journal of Hazardous Materials, Vol. 152, No. 2, 2008, pp. 589-600. doi:10.1016/j.jhazmat.2007.07.048

[21] H. P. Boehm, "Surface Oxides on Carbon and Their Analysis: A Critical Assessment," Carbon, Vol. 40, No. 2, 2002, pp. 145-149. doi:10.1016/S0008-6223(01)00165-8

[22] P. Janos, H. Buchtova and M. Ryznarova, "Sorption of Dye from Aqueous Solution onto Fly Ash," Water Research, Vol. 37, No. 20, 2003, pp. 4938-4944. doi:10.1016/j.watres.2003.08.011

[23] S. D. Khattri and M.K. Singh, "Removal of Malachite Green from Dye Wastewater Using Neem Sawdust by Adsorption," Journal of Hazardous Materials, Vol. 167, No. 1-3, 2009, pp. 1089-1094. doi:10.1016/j.jhazmat.2009.01.101

[24] B. K. Hamad, A. M. Noor, A. R. Afida and M. N. M. Asri, "High Removal of 4-Chloroguaiacol by High Surface Area of Oil Palm Shell-Activated Carbon Activated with $\mathrm{NaOH}$ from Aqueous Solution," Desalination, Vol. 257, No. 1-3, 2010, pp. 1-7. doi:10.1016/j.desal.2010.03.007

[25] A. Reffas, V. Bernardet, B. David, L. Reinerts, M. B. Lehocine, M. D. Batisse and L. Duciaux, "Carbon Prepared from Coffee Grounds by $\mathrm{H}_{3} \mathrm{PO}_{4}$ Activation: Characterization and Adsorption of Methylene Blue and Nylosan Red N-2RBL," Journal of Hazardous Materials, Vol. 175, No. 1-3, 2010, pp. 779-788. doi:10.1016/j.jhazmat.2009.10.076

[26] V. Boonamnuayvitaya, S. Sae-ung and W. Tanthapanichakoonc, "Preparation of Activated Carbons from Coffee Residue for the Adsorption of Formaldehyde," Separation and Purification Technology, Vol. 42, No. 2, 2005, pp. 159-168. doi:10.1016/j.seppur.2004.07.007

[27] H. Deng, G. L. Zhang, X. L. Xu, G. H. Tai and J. L. Dai, "Optimization of Preparation of Activated Carbon from Cotton Stalk by Microwave Assisted Phosphoric AcidChemical Activation," Journal of Hazardous Materials,
Vol. 182, No. 1-3, 2010, pp. 217-224. doi:10.1016/j.jhazmat.2010.06.018

[28] A. E. Nemr, O. Abdelwahab, E. A. Sikaily and A. Khaled, "A Removal of Direct Blue-86 from Aqueous Solution by New Activated Carbon Developed from Orange Peel," Journal of Hazardous Materials, Vol. 161, 2009, pp. 102110.

[29] V. K. Gupta, I. Ali, Subhas and D. Mohan, "Equilibrium Uptake and Sorption Dynamics for the Removal of a Basic Dye (Basic Red) Using Low-Cost Adsorbents," Journal of Colloid and Interface Science, Vol. 265, No. 2, 2003, pp. 257-264. doi:10.1016/S0021-9797(03)00467-3

[30] R. Ahmad and R. Kumar, "Adsorption Studies of Hazardous Malachite Green onto Treated Ginger Waste," Journal of Environmental Management, Vol. 91, No. 4, 2010, pp. 1032-1038. doi:10.1016/j.jenvman.2009.12.016

[31] B. H. Hameed, "Spent Tea Leaves: A Non-Conventional and Low-Cost Adsorbent for Removal of Basic Dye from Aqueous Solutions," Journal of Hazardous Materials, Vol. 161, No. 2-3, 2009, pp. 753-759. doi:10.1016/j.jhazmat.2008.04.019

[32] I. D. Mall, V. C. Srivastava, N. K. Agarwal and I. M. Mishra, "Adsorptive Removal of Malachite Green Dye from Aqueous Solution by Bagasse Fly Ash and Activated Carbon-Kinetic Study and Equilibrium Isotherm Analyses," Colloids and Surface Area: Physicochemical and Engineering Aspects, Vol. 264, No. 1-3, 2005, pp. 17-28. doi:10.1016/j.colsurfa.2005.03.027

[33] B. H. Hameed, D. K. Mahmoud and A. L. Ahmad, "Sorption of Basic Dye from Aqueous Solution by Pomelo (Citrus grandis) Peel in a Batch System," Colloids and Surface Area: Physicochemical and Engineering Aspects, Vol. 316, No. 1-3, 2008, pp. 78-84. doi:10.1016/j.colsurfa.2007.08.033

[34] E. S. Z. E. Ashtouskhy, "Loofa egyptiaca as a Novel Adsorbent for the Removal of Direct Blue Dye from Aqueous Solution," Journal of Environmental Management, Vol. 90, No. 6, 2009, pp. 2755-2761. doi:10.1016/j.jenvman.2009.03.005

[35] I. Langmuir, Journal of the American Chemical Society, Vol. 40, 1918, p. 1361.

[36] M. Dogan, M. Alkan and Y. Onganer, "Adsorption of Methylene Blue from Aqueous Solution onto Perlite," Water, Air and Soil Pollution, Vol. 120, No. 3-4, 2000, pp. 229-249. doi:10.1023/A:1005297724304

[37] I. Langmuir, "The Constitution and Fundamental Properties of Solids and Liquids," Journal of the American Chemical Society, Vol. 38, No. 11, 1916, pp. 2221-2295. doi: $10.1021 / \mathrm{ja} 02268 \mathrm{a} 002$

[38] D. G. Kinniburgh, "General Purpose Adsorption Isotherms," Environmental Science \& Technology, Vol. 20, No. 9, 1986, pp. 895-904. doi:10.1021/es00151a008

[39] E. Longhinotti, F. Pozza, L. Furlan, M. D. N. D. Sanchez, M. Klug, M. C. M. Laranjeira and V. T. Favere, "Adsorption of Anionic Dyes on the Biopolymer Chitin," Journal of the Brazilian Chemical Society, Vol. 9, No. 5, 1998, pp. 435-440. doi:10.1590/S0103-50531998000500005

[40] H. Freundlich, "User Die Adsorption in Losungen (Ad- 
sorption in Solution)," The Journal of Physical Chemistry, Vol. 57, 1906, pp. 384-470.

[41] B. Acemioglu, "Adsorption of Congo Red from Aqueous Solution onto Calcium-Rich Fly Ash," Journal of Colloid and Interface Science, Vol. 274, No. 2, 2004, pp. 371-379. doi:10.1016/j.jcis.2004.03.019

[42] J. P. Hobson, "Physical Adsorption Isotherms Extending from Ultrahigh Vacuum to Vapor Pressure," The Journal of Physical Chemistry, Vol. 73, No. 8, 1969, pp. 27202727. doi:10.1021/j100842a045

[43] M. J. Temkin and V. Pyzhev, "Recent Modifications to Langmuir Isotherms," Acta Physiochim, URSS 12, 1940, pp. 217-222.

[44] K. Y. Foo and B. H. Hameed, "Insights into the Modeling of Adsorption Isotherm Systems," Chemical Engineering Journal, Vol.156, No. 1, 2010, pp. 2-10. doi:10.1016/j.cej.2009.09.013

[45] A. C. Duran and I. Flores, "Evaluation of Lead (II) Immobilization by a Vermicompost Using Adsorption Isotherms and IR Spectroscopy," Bioresource Technology, Vol. 100, No. 4, 2009, pp. 1691-1694. doi:10.1016/j.biortech.2008.09.013

[46] G. Crini, H. N. Peindy, F. Gimbert and C. Robert, "Removal of C.I. Basic Green 4 (Malachite Green) from Aqueous Solutions by Adsorption Using CyclodextrinBased Adsorbent: Kinetic and Equilibrium Studies,"
Separation and Purification Technology, Vol. 53, No. 1, 2007, pp. 97-110. doi:10.1016/j.seppur.2006.06.018

[47] M. Ozacar and I. A. Sengil, "A Kinetic Study of Metal Complex Dye Sorption onto Pine Sawdust," Process Biochemistry, Vol. 40, No. 2, 2005, pp. 565-572. doi:10.1016/j.procbio.2004.01.032

[48] G. H. Sonawane and V. S. Shrivastava, "Kinetics of Decolourization of Malachite Green from Aqueous Medium by Maize Cob (Zea maize): An Agricultural Solid Waste," Desalination, Vol. 247, No. 1-3, 2009, pp. 430-441. doi:10.1016/j.desal.2009.01.006

[49] W. J. Weber and J. C. Morris, "Kinetics of Adsorption on Carbon from Solution," Journal of Sanity Engineering Division of the American Society of Civil Engineering, Vol. 89, 1963, pp. 31-59.

[50] Y. S. Ho, "Removal of Copper Ions from Aqueous Solution by Tree Fern," Water Research, Vol. 37, No. 10, 2003, pp. 2323-2330. doi:10.1016/S0043-1354(03)00002-2

[51] S. H. Chen, J. Zhang, C. G. Zhang, Q. Y. yue, Y. Li and C. Li, "Equilibrium and Kinetic Studies of Methyl Orange and Methyl Violet Adsorption on Activated Carbon Derived from Phragmites australis," Desalination, Vol. 252, No. 1-3, 2010, pp. 149-156. doi:10.1016/j.desal.2009.10.010 